\title{
A three-dimensional model for the seabed response induced by waves in conjunction with currents in the vicinity of an offshore pipeline using OpenFOAM.
}

\author{
Zuodong Liang \\ School of Engineering $\& 3$ Built Environment, Griffith University Gold Coast Campus, \\ QLD 4222, Australia \\ zuodong.liang@griffithuni.edu.au \\ Dong-Sheng Jeng \\ School of Engineering \& Built Environment, Griffith University Gold Coast Campus, \\ QLD 4222, Australia \\ d.jeng@griffith.edu.au \\ Received (Day Month Year) \\ Revised (Day Month Year)
}

\begin{abstract}
To better understand the physical processes involved in the wave-seabed-pipeline interactions (WSPI), a three-dimensional numerical model for the wave-induced soil response around an offshore pipeline is proposed in this paper. Seabed instability around an offshore pipeline is one of the key factors that need to be considered by coastal engineers in the design of offshore infrastructures. Most previous investigations into the problem of WSPI have only considered wave conditions and have not included currents, despite the co-existence of waves and currents in natural ocean environments. Unlike previous studies, currents are included in the present study for the numerical modelling of WSPI, using an integrated FVM model, in which the Volume-Averaged Reynolds-Averaged Navier-Stokes (VARANS) equation is used to solve the mean fluid field, while Biot's consolidation equation is used to describe the solid-pore fluid interaction in the porous medium. Numerical examples demonstrate a significant influence of ocean current direction and angle on the wave-induced pore pressures and the resultant seabed liquefaction around the pipeline, which cannot be observed in two-dimensional (2-D) numerical simulation.
\end{abstract}

Keywords: Wave-seabed-pipeline interactions (WSPI); wave-current interactions; Momentary liquefaction.

\section{Introduction}

Many offshore structures have been constructed over recent decades due to the growing use of marine resources. Submarine pipelines are an example of the popular offshore infrastructures and have been extensively used for the transportation of natural gas and oil from offshore platforms, and disposal of industrial and municipal waste. To ensure the safety of such submarine pipelines, coastal engineers have to consider unexpected loads including waves, currents, anchor dropping and dredging, 
which might cause its instability and decrease its lifespan. Thus, it is customary to bury the pipeline by trenching and refilling the soil; however, the cost is relatively high and it is time-consuming [Fredsøe, 2016].

Two mechanisms of dynamic wave-induced seabed liquefaction, momentary liquefaction and residual liquefaction, have been reported in the literature, based on the field measurements and laboratory experiments [Zen and Yamazaki, 1991; Nago et al., 1993]. The first mechanism, momentary (or oscillatory) liquefaction, can occur beneath wave troughs when the seepage flow is directed upward. Since this kind of liquefaction may happen within a short wave period near wave troughs, it is also called instantaneous liquefaction. The second mechanism is residual liquefaction, which is caused by compaction and cyclic shear processes, resulting in the accumulation of excess pore pressures in the seabed [Seed and Rahman, 1978]. As mentioned previously, the waves also can induce shear stresses in the soil when the waves propagate, which has been analytically investigated by Madsen [1978] and Yamamoto et al. [1978]. In the present study, the authors focus on the first mechanism.

Numerous investigations for the wave-induced sustained seabed response have been carried out based on the consolidation theory [Biot, 1941]. Among these, Yamamoto et al. [1978] obtained the exact closed-form analytical solutions for the wave-induced transient soil response in an isotropic, poro-elastic and infinite seabed. Hsu and Jeng [1994] proposed a 3D analytical solution for the pore pressure and effective stresses in a homogeneous unsaturated and anisotropic seabed with finite thickness. Later, this framework was further evaluated for soil liquefaction in a seabed with multiple sublayers [Hsu et al., 1995]. A detailed review of the relevant literature can be found in Jeng [2003].

Using wave flumes or centrifuges, numerous laboratory experiments have been conducted to investigate the wave-induced seabed response and the stability of submarine pipelines [Sumer et al., 1999, 2001; Teh et al., 2003; Zhou et al., 2011]. These experiments indicated that excessive seepage flow and the resulting piping are the major factors in causing the onset of scour beneath the pipeline. Furthermore, the experimental results showed that the pipeline behaviour mainly depends on its selfweight rather than the wave condition in a liquefied seabed [Teh et al., 2003].

With the rapid development of computational techniques and facilities, numerical simulations on the wave-seabed-structure interaction allows researchers to simulate large-scale and realistic models and to couple soil and fluid models. Different numerical methods, including the finite element method (FEM), finite difference method (FDM) and boundary element method (BEM) [Cheng and Liu, 1986; Jeng and Lin, 1999; Jeng and Cheng, 2000] have been applied to simulate the dynamic wave-induced seabed response as well as seabed instability. Later, several FEM models were built to investigate more complicated Wave-Seabed-Structure Interactions (WSSI) involving a fully buried pipeline in a trenched layer or a multi-layered and anisotropic seabed [Gao et al., 2003; Gao and Wu, 2006; Zhou et al., 2013]. However, there is a major limitation of the above studies, which is that the effect of linear or 
non-linear waves was evaluated from the analytical solutions. Consequently, these models may not be able to predict the seabed response around a pipeline that is partly buried or mounted on the seabed. Recently, Zhao et al. [2014] and Lin et al. [2016] proposed a FEM model to remedy these limitations. However, their numerical models are limited to a 2-D model due to the lack of 3-D wave model developed in COMSOL.

In natural ocean environments, ocean waves and currents generally exist simultaneously, however, most previous investigations only considered wave conditions and did not include currents. To consider the impact of ocean currents on the WSPI problem, Wen et al. [2012] developed a FEM model to study the elastic seabed with a fully embedded pipeline by using ABAQUS. Later, Zhou et al. [2014] proposed a FEM seabed model to investigate the wave-current interactions around a buried pipeline in an anisotropic seabed. More recently, Duan et al. [2017] developed an integrated FEM model to study the oscillatory soil response involving a partially buried pipeline. However, those studies only considered the co-current and counter-current as a $2-\mathrm{D}$ problem. In fact, ocean waves propagate along with oblique ocean currents, thus inducing a different distribution of pore-water pressures on the seabed. Therefore, it is necessary to investigate the influence of interactions between the waves and oblique currents on the seabed response.

Numerical modelling has been generally employed as a productive approach for investigate the seabed response induced to various wave conditions. CFD computations within the framework of OpenFOAM based on the Finite Volume Method (FVM), a free open source $\mathrm{C}++$ library for various fluid flow and solid mechanics problems, have been used to simulate fully non-linear wave-structure interactions. Zhao et al. [2014] and Liu and García [2007] first discretized the Biot's consolidation equations in a FVM manner within OpenFOAM and then investigated the wave-induced response around the submerged object. Tang et al. [2015] extended and modified the poro-elastic Biot's model to a poro-elasto-plastic soil model. Lin et al. [2017] proposed a segregated FVM solver to address the issue of a non-linear wave-induced dynamic seabed response surrounding a mono-pile foundation. However, their studies have mostly focused on the investigation of interactions between waves and seabed around a mono-pile or a breakwater. More recently, Liang and Jeng [2018] proposed a 3-D FVM-FEM integrated model to analyse the instability induced by the sloping seabed geometry in the vicinity of offshore pipelines. To date, the effect of 3-D ocean currents on the stability of seabed foundations have not been fully investigated.

In this paper, a 3-D integrated numerical model for transient soil components in the vicinity of a submarine pipeline under the combined loads of progressive waves and oblique ocean currents is presented. The present model was developed within the open source code OpenFOAM. Both wave and seabed models are developed and integrated within the framework of the FVM. In the following sections, details of the numerical framework will be presented and then the developed model is veri- 
fied through comparison with the experimental data available in the literature to ensure its accuracy and effectiveness. Following the validations, the developed numerical model is applied to investigate wave-seabed-structure interactions around a submarine pipeline. Both the hydrodynamic process of the the interactions between the non-linear wave (current) and submarine pipeline and the associated dynamics of the wave-induced soil response are analysed. Finally, the effects of the key parameters (i.e. wave and soil characteristics, current velocities and pipeline configuration) on wave-induced soil liquefaction leading to instability of the structure will be investigated through parametric studies.

\section{Numerical model}

Figure 1 shows the schematic diagram of the model in this study. The submarine pipeline with the outer diameter $D_{p}$ within a porous seabed $\left(L_{s} \times W_{s}\right)$ is considered. The fifth-order Stokes wave theory is for wave generation with a fixed water depth $d_{w}$ that propagates in the positive $x$ - direction; in terms of the ocean currents $U_{c}$, they are continuously generated and enter the flow domain along the positive $y$ - direction with an intersection angle $(\alpha)$ with the previous incoming waves; $z-$ direction is upward from the impermeable bottom of the porous seabed. Both the non-linear waves and ocean currents are numerically absorbed by the corresponding outlet for eliminating wave reflections within the fluid field.

\subsection{Wave model}

In this study, a FVM hydrodynamic model based on the VARANS equation proposed by del Jesus et al. [2012] is developed in the open-source CFD toolbox OpenFOAM, to investigate the wave-current-pipeline interactions. The modified version of the porous interfoam solver (porousInterFoam) is adopted to solve the VARANS equations using the combined algorithm PIMPLE (which is created by merging the PISO and SIMPLE algorithms) for pressure-velocity coupling. The IHFoam toolbox [Higuera et al., 2013] is used for the generation/absorption of water waves and steady currents inside the domain by imposing the water surface elevation and the flow velocity field via a relaxation function. Therefore, the governing equation for simulating the two-phase incompressible flow motion, which include the conservation of mass, conservation of momentum and the VOF function advection equation are shown below:

$$
\frac{\partial \alpha_{1}}{\partial t}+\frac{1}{n} \frac{\left\langle u_{i}\right\rangle \alpha_{1}}{\partial x_{i}}+\frac{1}{n} \frac{\partial\left\langle u_{c_{i}}\right\rangle \alpha_{1}\left(1-\alpha_{1}\right)}{\partial x_{i}}=0
$$


fraction $\left(\alpha_{1}\right)$, one can represent the spatial variation in any fluid property, such as density and viscosity, and considering the mixture properties:

$$
\Phi=\alpha_{1} \Phi_{w}+\left(1-\alpha_{1}\right) \Phi_{a},
$$

in which $\Phi_{w}$ and $\Phi_{a}$ is any kind of property of water and air, respectively.

In the wave model, several boundary conditions need to be specified since the wave generation is considered an important element of numerical coastal engineering simulation. The $5^{\text {th }}$ Stokes wave theory [Fenton, 1985] is adopted to generate the progressive waves for the inlet condition. Meanwhile, an active wave absorption theory is employed to prevent the re-reflection of incoming waves at the outlet. The seabed surface boundary is defined as a slip boundary condition. A pressure outlet condition is used for the atmospheric boundary at the upper boundary of the fluid domain. The detailed information for describing the wave generation and wave absorption can be found in Higuera et al. [2013].

\subsection{Seabed model}

The seabed model is also established under the framework of OpenFOAM (version 4.0), which is a finite-volume analysis source code. In particular, the quasi-static Biot equation [Biot, 1941] is employed to describe the mechanical behaviour of a hydraulically isotropic porous elastic seabed with appropriate boundary conditions. In this study, the wave profiles and their corresponding dynamic wave pressure are extracted from the wave model as the surface boundary at the seabed surface, and the outer surface of the submarine pipeline.

In general, the soil-pore fluid interaction is determined with Biot's consolidation equation [Biot, 1941], in which the soil skeleton is considered as an elastically isotropic material; the pore fluid is assumed to be compressible and to obey Darcy's law, but neglects the acceleration due to pore fluid and soil motion. For a 3-D problem, the governing equations can be expressed as

$$
\nabla^{2} \tilde{p}_{s}-\frac{\gamma_{w} n_{s} \beta_{s}}{k_{s}} \frac{\partial \tilde{p}_{s}}{\partial t}=\frac{\gamma_{w}}{k_{s}} \frac{\partial}{\partial t}\left(\frac{\partial u_{s}}{\partial x}+\frac{\partial v_{s}}{\partial y}+\frac{\partial w_{s}}{\partial z}\right),
$$

where $\tilde{p}_{s}$ is the wave-induced pore pressure; $\gamma_{w}$ is the unit weight of the pore water; $n_{s}$ is the soil porosity; $\epsilon_{s}$ is the volume strain defined by

$$
\epsilon_{s}=\frac{\partial u_{s}}{\partial x_{s}}+\frac{\partial v_{s}}{\partial y_{s}}+\frac{\partial w_{s}}{\partial z_{s}}
$$

where $u_{s}, v_{s}$ and $w_{s}$ are the soil displacements in the $x-, y-$ and $z-$ directions, respectively. $\beta_{s}$ denotes the compressibility of the pore fluid, which is related to the apparent bulk modulus of the pore fluid and the degree of saturation, such that

$$
\beta_{s}=\frac{1}{K_{w}}+\frac{1-S_{r}}{P_{w 0}}
$$


where $K_{w}$ is the true bulk modulus of the elasticity of water (which may be taken as $1.95 \times 10^{9} \mathrm{~N} / \mathrm{m}^{2}$ ) and $P_{w o}$ is the absolute water pressure. When the soil is fully saturated, i.e. it is completely air-free, then $\beta_{s}=1 / K_{w}$ since $S_{r}=1$.

The equation for the overall equilibrium in a porous-elastic medium, relating to the effective stresses and pore pressure, is given by

$$
\begin{gathered}
\frac{\partial \sigma_{x}^{\prime}}{\partial x}+\frac{\partial \tau_{x y}}{\partial y}+\frac{\partial \tau_{x z}}{\partial z}=\frac{\partial \tilde{p}_{s}}{\partial x} \\
\frac{\partial \tau_{x y}}{\partial x}+\frac{\partial \sigma_{y}^{\prime}}{\partial y}+\frac{\partial \tau_{y z}}{\partial z}=\frac{\partial \tilde{p}_{s}}{\partial y} \\
\frac{\partial \tau_{x z}}{\partial x}+\frac{\partial \tau_{y z}}{\partial y}+\frac{\partial \sigma_{z}^{\prime}}{\partial z}=\frac{\partial \tilde{p}_{s}}{\partial z}
\end{gathered}
$$

where Cauchy stress tensor on the adjacent faces of a stress element consists of three effective normal stresses and six shear stress components respectively, the shear stresses are expressed in double subscripts $\tau_{r s}$, defining the stress in the $s-$ direction on a plane perpendicular to the $r$ - axis.

Based on the generalised Hookes law, the governing equations for the force equilibrium in the soil can be written as

$$
\begin{gathered}
G_{s} \nabla^{2} u_{s}+\frac{G_{s}}{\left(1-2 \mu_{s}\right)} \frac{\partial \epsilon_{s}}{\partial x}=\frac{\partial \tilde{p}_{s}}{\partial x} \\
G_{s} \nabla^{2} v_{s}+\frac{G_{s}}{\left(1-2 \mu_{s}\right)} \frac{\partial \epsilon_{s}}{\partial y}=\frac{\partial \tilde{p}_{s}}{\partial y} \\
G_{s} \nabla^{2} w_{s}+\frac{G_{s}}{\left(1-2 \mu_{s}\right)} \frac{\partial \epsilon_{s}}{\partial z}=\frac{\partial \tilde{p}_{s}}{\partial z}
\end{gathered}
$$

in which $\nabla$ is the Laplace operator, $G_{s}$ is the shear modulus of soil, which is related to Young's modulus $(E)$ and Poisson's ratio $\left(\mu_{s}\right)$ as $E / 2\left(1+\mu_{s}\right)$.

In the present model, the linear reversible behaviour of the soil skeleton is considered. This assumption was commonly used in the previous studies for the waveinduced instantaneous seabed response over a relatively short time scale and gave satisfactory results [Hsu and Jeng, 1994; Ulker and Rahman, 2009]. Under conditions of plane strain, the stress-strain relationship obeys Hooke's law;

$$
\begin{aligned}
& \sigma_{x}^{\prime}=2 G_{s}\left[\frac{\partial u_{s}}{\partial x}+\frac{\mu}{1-2 \mu} \varepsilon_{s}\right], \sigma_{y}^{\prime}=2 G_{s}\left[\frac{\partial v_{s}}{\partial y}+\frac{\mu}{1-2 \mu} \varepsilon_{s}\right] \\
& \sigma_{z}^{\prime}=2 G_{s}\left[\frac{\partial w_{s}}{\partial z}+\frac{\mu}{1-2 \mu} \varepsilon_{s}\right], \tau_{x y}=G_{s}\left[\frac{\partial u_{s}}{\partial y}+\frac{\partial v_{s}}{\partial x}\right]=\tau_{y x}
\end{aligned}
$$




$$
\tau_{x z}=G_{s}\left[\frac{\partial u_{s}}{\partial z}+\frac{\partial w_{s}}{\partial x}\right]=\tau_{z x}, \tau_{y z}=G_{s}\left[\frac{\partial v_{s}}{\partial z}+\frac{\partial w_{s}}{\partial y}\right]=\tau_{z y} .
$$

Note that a positive sign is taken as being a compressive normal stress in this study.

Several boundary conditions are employed at the boundary of the seabed domain and the surface of the submarine pipeline for evaluating the wave-current-seabedstructure interaction accurately. At the seabed surface, the wave-induced pore-water pressure $\tilde{p}_{s}$ is equal to the value of $p_{w}$ from the wave model, and the vertical effective normal stress and shear stresses are considered to vanish:

$$
\tilde{p}_{s}=p_{w}, \sigma_{z}^{\prime}=\tau_{x z}=\tau_{y z}=0 \text { at } z=0
$$

At the bottom of the seabed, an impermeable rigid boundary condition is applied, in which the soil displacement and vertical flow gradient are considered to be zero:

$$
u_{s}=v_{s}=w_{s}=\frac{\partial \tilde{p}_{s}}{\partial z}=0, \text { at } z=-h_{s}
$$

In relation to the lateral boundaries, no flow (zero gradient) and zero soil displacement boundary conditions are employed:

$$
u_{s}=v_{s}=w_{s}=\frac{\partial \tilde{p}_{s}}{\partial x}=0, \text { at } x=0 \text { and } x=L_{s}
$$

$$
u_{s}=v_{s}=w_{s}=\frac{\partial \tilde{p}_{s}}{\partial y}=0, \text { at } y=-W_{s} / 2 \text { and } y=W_{s} / 2
$$

To avoid any computational error due to the reflective waves from the lateral boundary, a large computational domain which is three times the wavelength, is applied by fixing two lateral boundaries in the horizontal direction, which has been proved to be sufficient for the seabed domain [Ye and Jeng, 2012]. Additionally, the submarine pipeline is simulated as a rigid impermeable object in which the no-flow boundary condition is applied at its surface:

$$
\frac{\partial p_{w}}{\partial \boldsymbol{n}}=0
$$

where $\boldsymbol{n}$ represents the direction normal to the surface of the submarine pipeline; this boundary condition is acceptable for a rigid object located within a porous seabed.

\subsection{Integration of wave and seabed models}

Unlike the previous 2-D or 3-D numerical models that used the FEM model, the present model is established in OpenFOAM under the framework of FVM. In the model integration, a one-way coupling algorithm is applied to two separate domains 


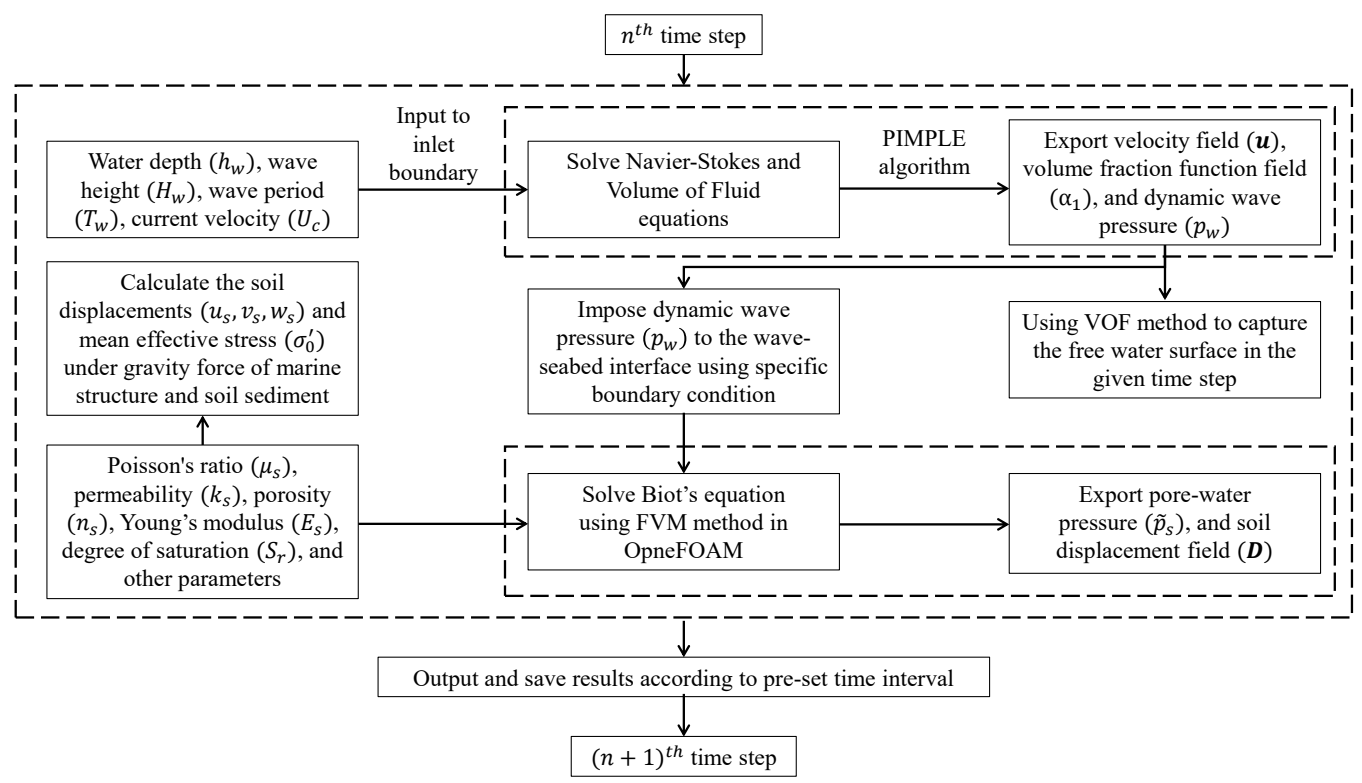

Fig. 2. Coupled process in the integrated WSPI model in OpenFOAM.

and communication takes place at the boundaries between both sub-models in one direction. The model sensitivity analysis demonstrates that the time interval and grid resolutions required for the wave domain for its convergent is much smaller than those required for the solid domain. To optimize the computational cost, we adopted a non-matching time scheme in combination with a non-matching mesh system in the one-way coupling process after the simulation of the hydrodynamic process is completed. The procedure of this integrated WSPI model is outlined in Figure 2. More precisely, in accordance with the input wave parameters, the wave model solves the Navier-Stokes and Volume of Fluid equations by applying the least square linear reconstruction (LSLR) method [Barth, 1992]. To obtain computational stability, the time interval is automatically adjusted to satisfy the Courant-Friedrichs-Lewy condition and the diffusive limit condition [Liu et al., 1999], with a range between $0.005 \mathrm{~s}$ and $0.05 \mathrm{~s}$. Secondly, the dynamic wave pressure at each time step is interpolated to the grid points of the seabed model at the interface, forcing the seabed model to the pressure boundary condition. Next, the seabed model can be timedependently solved to obtain the wave-induced dynamics of the seabed and marine structures, including the field of displacements, pore-water pressures, and effective stresses, etc. Finally, the integrated model exports the simulated results based on the pre-set writing time interval and then continues to the next time step simulation until the prescribed total simulation time is reached. 


\subsection{Model validations}

In this study, the developed FVM model is systematically validated using five sets of published laboratory experimental results available in the literature (as listed below). The wave and soil parameters considered in the numerical simulations for verification are the same as those used in the laboratory experiments unless specified.

(1) Umeyama [2011]-coupled PIV and PTV measurements of particle velocities for progressive wave following a steady current

(2) Mattioli et al. [2012]'s laboratory investigation of the near-bed dynamic interaction between regular waves and the submarine pipeline

(3) Hsu and Jeng [1994]'s analytical solution and Liu et al. [2015]'s experiment data of pore-water pressure $\tilde{p}_{s}$

(4) Turcotte et al. [1984]'s laboratory experiment and Cheng and Liu [1986]'s numerical solution of the wave-induced soil response around a fully buried pipeline

(5) Sun et al. [2018]'s experimental study of ocean waves propagating over a partially buried pipeline in a trench layer

In this section, only the comparison with the Sun et al. [2018]'s experiment is presented, since their physical study involving the engineering problem is closest to that of our numerical simulation. The other four sets of experimental comparisons is presented in the Appendix.

Sun et al. [2018] conducted a series of comprehensive laboratory experiments in a wave flume to study the pore pressure caused by waves around partially embedded pipes in the trench layer. The experiments were carried out in a wave flume that was $55.0 \mathrm{~m}$ in length, $1.3 \mathrm{~m}$ in height and $1.0 \mathrm{~m}$ in width at the laboratory of Hohai University, China. A piston-type wave generator at the upstream end and a spongetype wave absorber at the downstream end dissipated the incident wave energy and eliminated wave reflection. A sediment basin was located at a distance of $25 \mathrm{~m}$ away from the wave maker, and its thickness was maintained at $0.58 \mathrm{~m}$. The PMMA pipe with a diameter of $0.10 \mathrm{~m}$ was used to model the submarine pipelines located at the bottom of a trenched layer. During the experiments, eight sets of pore pressure transducers were set-up around the pipeline circumference with an interval of $\pi / 4$, and others were fixed along the central line just below the trench at three different depths $(z=-0.23 m,-0.27 m$ and $-0.40 m)$, as indicated in Figure 3 .

Figure 4 presents the comparison between the simulated and measured maximum amplitudes of the pore-water pressure $\left(\left|\tilde{p}_{s}\right| / p_{0}\right)$ around the outer surface of the submarine pipeline for Test No.10 and No.49. More specifically, a pipeline was fully buried in a trench with depth $\left(d_{t}\right)=0.15 \mathrm{~m}$ and covered by the backfill with thickness $\left(d_{b}\right)=0.15 \mathrm{~m}$ in Test No.10. Test 49involved a partially buried pipeline in a trench where $d_{t}=0.2 \mathrm{~m}$ and $d_{b}=0.05 \mathrm{~m}$. The wave characteristics of the two tests (No.10 and No.49), including wave height and wave period, were $0.14 \mathrm{~m}$ at $1.4 \mathrm{~s}$ and 0.12 $m$ at $1.6 \mathrm{~s}$, respectively.

Figure 5 further shows a comparison of the maximum amplitudes of the pore- 
Table 1. Parameters for Sun et al. [2018]'s laboratory experiment.

\begin{tabular}{lll}
\hline Characteristics & Value & Unit \\
\hline Wave characteristics & & \\
Wave height $\left(H_{w}\right)$ & 0.14 or 0.12 & {$[\mathrm{~m}]$} \\
Water depth $\left(d_{w}\right)$ & 0.4 & {$[\mathrm{~m}]$} \\
Wave period $\left(T_{w}\right)$ & 1.4 or 1.6 & {$[\mathrm{~s}]$} \\
\hline Soil characteristics & & \\
Permeability $\left(k_{s}\right)$ & $3.56 \times 10^{-5}$ & {$[\mathrm{~m} / \mathrm{s}]$} \\
Poisson's ratio $\left(\mu_{s}\right)$ & 0.32 & - \\
Porosity $\left(n_{s}\right)$ & 0.396 & - \\
Degree of saturation $\left(S_{r}\right)$ & 100 & $\%$ \\
Shear modules $\left(G_{s}\right)$ & $10^{7}$ & {$\left[\mathrm{~N} / \mathrm{m}^{2}\right]$} \\
\hline Pipeline characteristics & & \\
Pipeline diameter $\left(D_{p}\right)$ & 0.1 & {$[\mathrm{~m}]$} \\
\hline
\end{tabular}

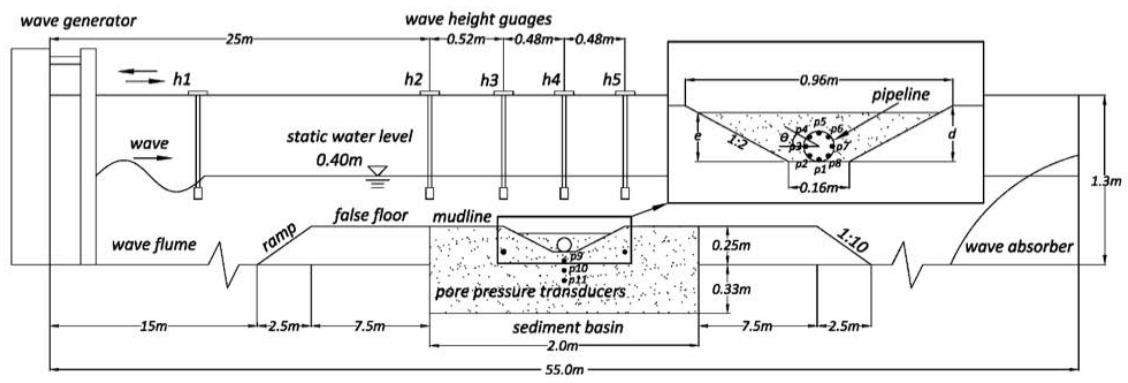

Fig. 3. Experimental set-up of wave flume tests [Sun et al., 2018] for the validation of the present model.

water pressure $\left(\left|\tilde{p}_{s}\right| / p_{0}\right)$ versus time at different measurement points beneath the pipeline (i.e. $z / h=-0.411$ and -0.482 , respectively). It is noted that the soil properties remained the same in both tests. As can be seen from the figures, the numerical results overall agree with experimental data.

Overall, the present seabed model established in OpenFOAM can accurately simulate the wave-induced dynamic seabed response involving both a fully-buried and trenched pipeline.

\section{Applications}

This paper aims to develop a 3-D integrated numerical model to investigate the momentary liquefaction around an offshore pipeline. In this study, the combined effects of the wave, current and seabed together with the configuration of the marine 


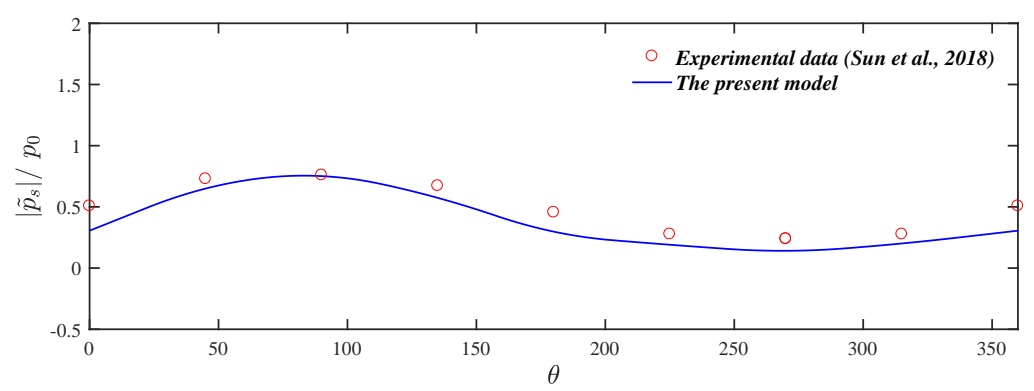

(a) Test $10\left(d_{t}=d_{b}=0.15 \mathrm{~m}\right)$

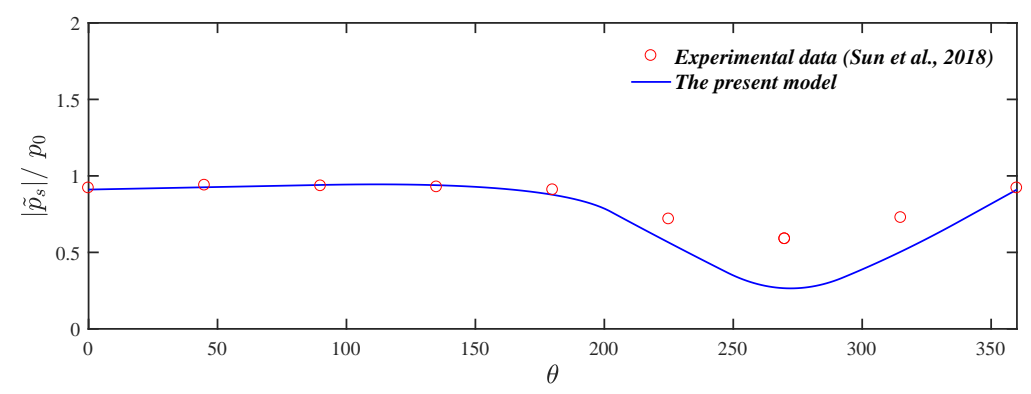

(b) Test $49\left(d_{t}=0.2 \mathrm{~m} ; d_{b}=0.05 \mathrm{~m}\right)$

Fig. 4. Comparison of wave-induced pore pressure with laboratory experimental data [Sun et al., 2018] for Test 10 and 49 along the periphery of the pipe.

structure on the pore-water pressure around the buried pipeline are examined. All the wave and current characteristics, as well as properties of the sandy seabed and submarine pipeline are listed in Table 2 unless specified.

In order to investigate the effect of a specific parameter on the wave-induced oscillatory soil liquefaction around the offshore pipeline under the combined loads of ocean waves and oblique currents, the maximum pore-water pressure $\left(\left|\tilde{p}_{s}\right| / p_{0}\right.$, where $p_{0}$ is the amplitude of non-linear wave loads) is discussed in two different situations, i.e. $W C M N$ and $W A M N$. These two situations represent the cases with wave + current and wave alone, respectively. $M$ is the abbreviation for corresponding variables, such as wave height $\left(H_{w}\right)$, water depth $\left(d_{w}\right)$, soil permeability $\left(k_{s}\right)$, degree of saturation $\left(S_{r}\right)$, burial depth $(e)$ and diameter of pipeline $\left(D_{p}\right)$ while $N$ is the serial number of each case.

Since non-linear wave theory is used in the study, the maximum and minimum amplitudes under the combined loads of wave and current are compared with the linear wave theory. While the instability of the seabed (i.e., soil liquefaction) generally occurs near wave troughs, it is also necessary to clarify that, only the maximum absolute amplitude of pore-water pressure $\left|\tilde{p}_{s}\right|$ near wave troughs is considered here, 

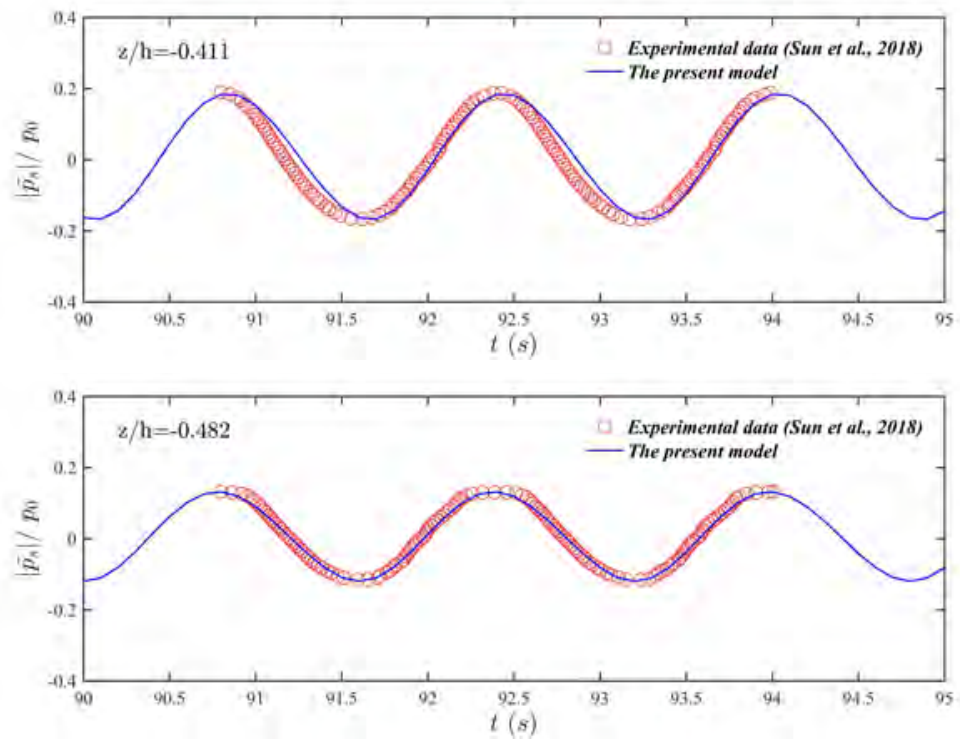

(a) Test $10\left(d_{t}=d_{b}=0.15 \mathrm{~m}\right)$
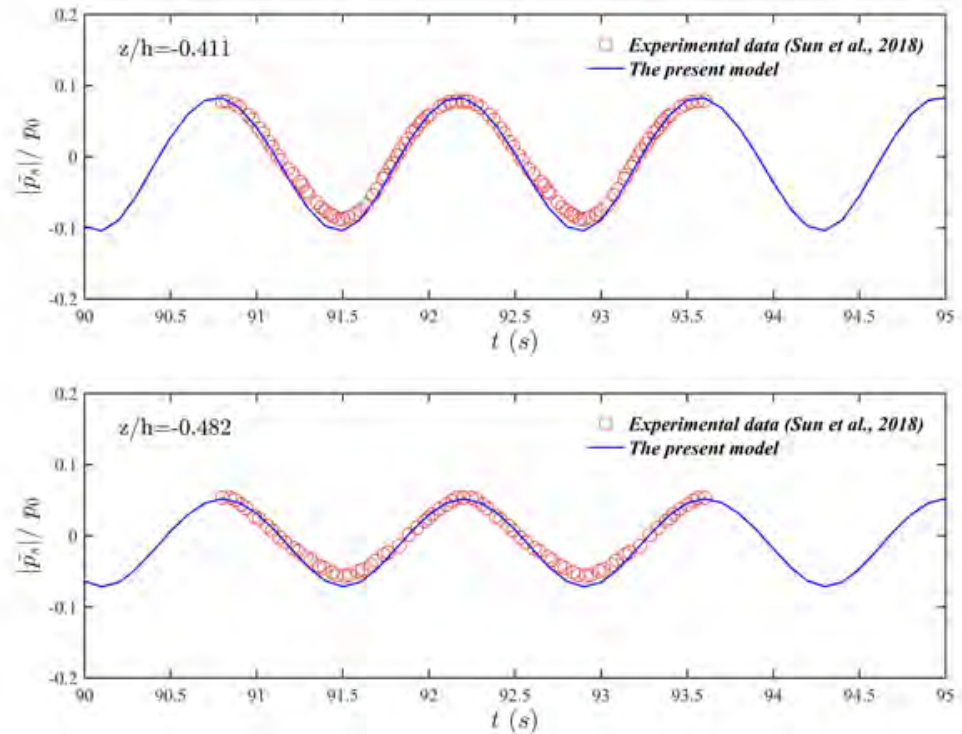

(b) Test $49\left(d_{t}=0.2 \mathrm{~m} ; d_{b}=0.05 \mathrm{~m}\right)$

Fig. 5. Comparison of wave-induced pore pressure with laboratory experimental data [Sun et al., 2018] for Tests 10 and 49 through the centre of the pipe. Note: $z / h=0$ denotes the seabed surface in the experiments, where $h$ is the seabed thickness.

as $\tilde{p}_{s}$ is usually expressed as a negative value and is generating an upward pressure gradient in the seabed.

To further examine the effect of ocean currents on the seabed instability in 
Table 2. Parameters for studying fluid-seabed-pipeline interaction.

\begin{tabular}{lll}
\hline Characteristics & Value & Unit \\
\hline Wave characteristics & & \\
Wave height $\left(H_{w}\right)$ & 2.0 or various & {$[\mathrm{m}]$} \\
Water depth $\left(d_{w}\right)$ & 8.0 or various & {$[\mathrm{m}]$} \\
Wave period $\left(T_{w}\right)$ & 6.0 & {$[\mathrm{~s}]$} \\
Specific weight of water $\left(\gamma_{s}\right)$ & 9.8 & {$\left[\mathrm{kN} / \mathrm{m}^{3}\right]$} \\
Viscosity of water $(\nu)$ & $10^{-6}$ & {$\left[\mathrm{~m}^{2} / \mathrm{s}\right]$} \\
\hline Current characteristics & & \\
Velocity $\left(U_{c}\right)$ & 1.0 & {$[\mathrm{~m} / \mathrm{s}]$} \\
Interaction angle $(\alpha)$ & 30 or various & {$\left[{ }^{\circ}\right]$} \\
\hline Soil characteristics & & \\
Permeability $\left(k_{s}\right)$ & $1.0 \times 10^{-3}$ or various & {$[\mathrm{m} / \mathrm{s}]$} \\
Poisson's ratio $\left(\mu_{s}\right)$ & 0.33 & - \\
Young's modulus $\left(E_{s}\right)$ & $5.0 \times 10^{7}$ & {$[\mathrm{~Pa}]$} \\
Porosity $\left(n_{s}\right)$ & 0.425 & - \\
Degree of saturation $\left(S_{r}\right)$ & 96.8 or various & $\%$ \\
Shear modules $\left(G_{s}\right)$ & $10^{7}$ & {$[\mathrm{~N} / \mathrm{m} 2]$} \\
Specific weight of soil grains $\left(\gamma_{s}\right)$ & 10.71 & {$\left[\mathrm{kN} / \mathrm{m}^{3}\right]$} \\
Seabed thickness $(h)$ & 15 & {$[\mathrm{~m}]$} \\
Seabed width $\left(W_{s}\right)$ & 100 & {$[\mathrm{~m}]$} \\
Seabed length $\left(L_{s}\right)$ & 100 & {$[\mathrm{~m}]$} \\
\hline Pipeline characteristics & & \\
Young's modulus $\left(E_{b}\right)$ & $2.09 \times 10^{11}$ & {$[\mathrm{~Pa}]$} \\
Pipeline diameter $\left(D_{p}\right)$ & 1.0 or various & {$[\mathrm{m}]$} \\
Burial depth $(e)$ & 1.0 or various & {$[\mathrm{m}]$} \\
Poisson's $\left(\mu_{p}\right)$ & 0.32 & - \\
Specific weight of pipeline $\left(\gamma_{p}\right)$ & 15 & {$\left[\mathrm{kN} / \mathrm{m}^{3}\right]$} \\
\hline
\end{tabular}

the vicinity of a submarine pipeline, the relative difference of pore-water pressure $\left(\left|\Delta \tilde{p}_{s}\right| / p_{0}\right)$ is investigated in the following sections. $\Delta \tilde{p}_{s}$ is defined as $p_{\text {wave\&current }}-$ $p_{\text {wave-alone }}$, where $p_{\text {wave\&current }}$ is the numerical results from co-action of the $5^{\text {th }}$ order waves and an oblique ocean currents, while $p_{\text {wave-alone }}$ is that of $5^{\text {th }}$ order wave loads only. Note that when discussing the distribution of $\left|\Delta \tilde{p}_{s}\right| / p_{0}$ in the case involving the oblique ocean currents, the interaction angles $(\alpha)$ between ocean currents and incoming waves are all $30^{\circ}$ unless specified. 

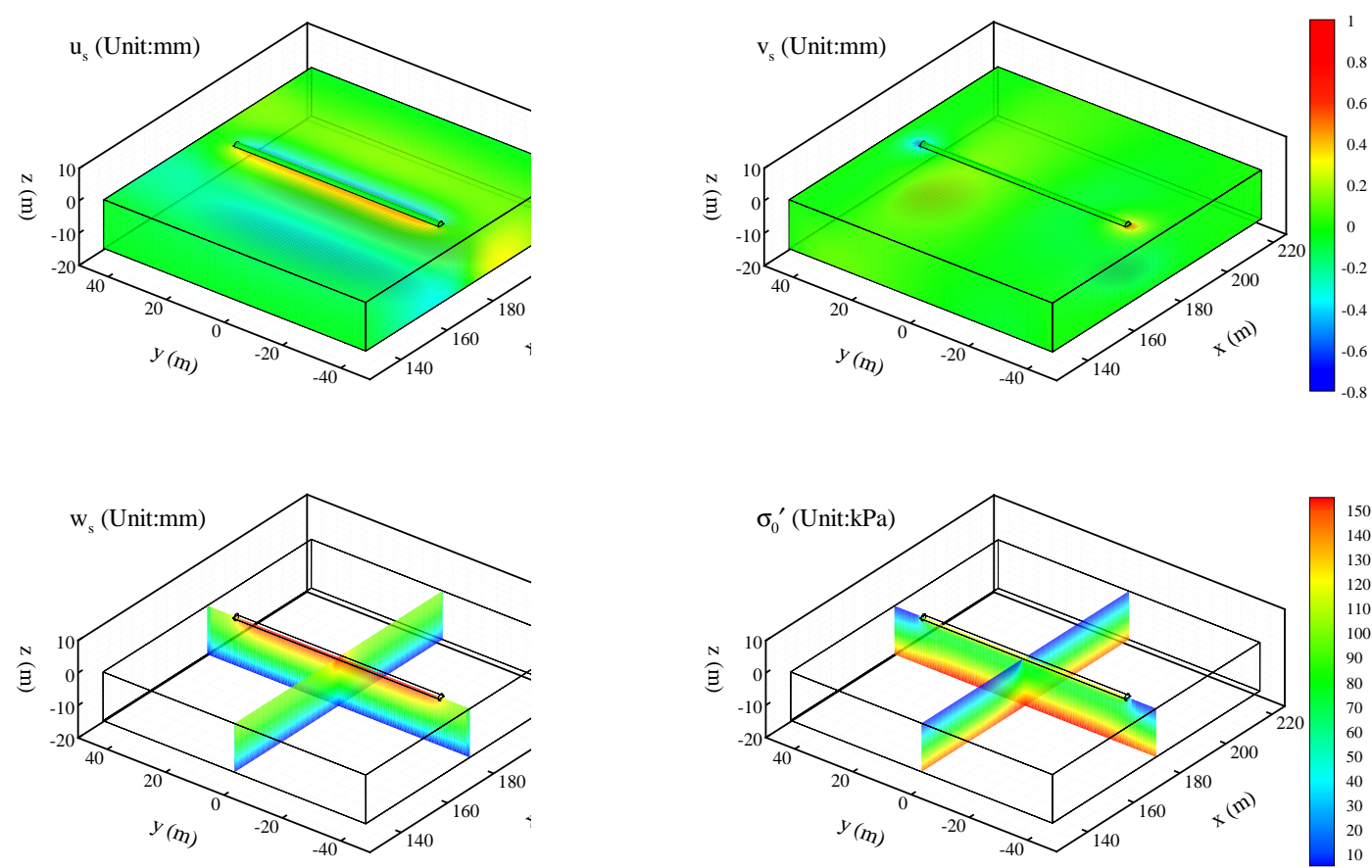

Fig. 6. Distribution of displacements and mean normal effective stress in the seabed foundation after completion of consolidation.

\subsection{Consolidation of the seabed}

In natural offshore environments, the seabed generally has experienced the consolidation process under gravitational forces in its geological history. However, after submarine infrastructures are constructed, due to the effect of the body forces of the structure, the seabed will then reach a new balanced state, based on the previous consolidation state under static loads.

In this study, the actual in-situ effective stress after the consolidation is considered with the static loads including the self-gravity of the submarine pipeline, as well as the self-weight of the marine sediment. Then, the in-situ effective stresses are applied as the initial conditions in the following dynamic analysis of wave-seabedstructure interactions.

Figure 6 shows the distribution of soil displacements $\left(u_{s}, v_{s}\right.$ and $\left.w_{s}\right)$, as well as mean normal effective stress $\left(\sigma_{0}^{\prime}\right)$, in the seabed foundation after completion of the consolidation process under gravitational forces. As shown in the figure, the seabed foundation in the surrounding areas of the structure tends to move away from the structure and to subside downward during the process of gravitational consolidation. Furthermore, the numerical results indicate that the soil underneath 
the pipe is compressed significantly with a large amplitude of $\left|\sigma_{0}^{\prime}\right|$ with regrades to its lateral sides due to the large value of the specific gravity of the pipe. In these regions, the excess pore-water pressure is unlikely to exceed the increased effective stress, thereby reducing the likelihood of liquefaction of the sand deposit.

\subsection{Wave non-linearity and current}

Figure 7 shows several snapshots of the wave-current field from a 3-D perspective. The wave field above the porous seabed is highly three-dimensional. The shape of the incoming waves is altered significantly by the influence of ocean currents. As a result, the length of the wave trough near the entrance to the ocean currents becomes shorter compared to the incoming waves at the far end. At the same time, the wave height of the incoming waves decreases as the distance from the inlet of the ocean currents becomes shorter. With respect to the variation of the free water surface, it can be more significantly affected by the marine structures that are situated in free water (e.g., mono-piles and caisson-breakwaters). The flow field near such structures will further alter the distribution of wave-induced pore-water pressure. Overall, Figure 7 directly shows how the oblique ocean currents interact with the progressive waves, for instance, the three-dimensional variation of wave height and the wavelength. With the change in the free surface elevation, the hydrodynamic loads will further alter the distributions of pore-water pressure around the submarine pipeline.

Figure 8 presents the distributions of the pore-water pressure $\left(\left|\tilde{p}_{s}\right| / p_{0}\right)$ as well as the relative difference in the pore-water pressure $\left(\left|\Delta \tilde{p}_{s}\right| / p_{0}\right)$ along the periphery of the pipeline and the vertical line through the centre of the pipeline for different combination of waves and currents. As illustrated in the figure, ocean currents velocity $\left(U_{c}\right)$ with a larger amplitude can immediately increase $\left|\tilde{p}_{s}\right| / p_{0}$ around the submarine pipeline. Additionally, $\left|\Delta \tilde{p}_{s}\right| / p_{0}$ increases as the ocean currents velocity $\left(U_{c}\right)$ increases along the periphery of the pipeline resulting in an asymmetrical distribution, which may be due to the phase lags of the pore-water pressure within the soil under the combined loads of progressive waves and ocean currents. Another interesting observation from the figure is that the vertical distribution of $\left|\Delta \tilde{p}_{s}\right| / p_{0}$ is larger in the upper thickness of the seabed when the ocean currents velocity $\left(U_{c}\right)$ is equal to $2.0 \mathrm{~m} / \mathrm{s}$. This clearly indicates that the effects of wave non-linearity and currents become more significant near the upstream side of the pipeline and the upper layer of the porous seabed with stronger ocean currents.

Figure 9 illustrates the distribution of maximum pore-water pressure $\left(\left|\tilde{p}_{s}\right| / p_{0}\right)$ along the periphery of the submarine pipeline and the vertical line through its centre with a different interaction angle $(\alpha)$, respectively. From the figure, the increase in the interaction angle between the incoming waves and the ocean currents will reduce the response of the pore-water pressure $\left(\left|\tilde{p}_{s}\right| / p_{0}\right)$ around the semi-buried pipeline. This maybe because when the wave-current interaction angle is greater than $90^{\circ}$, some of the ocean currents block the propagation of the incident wave. 

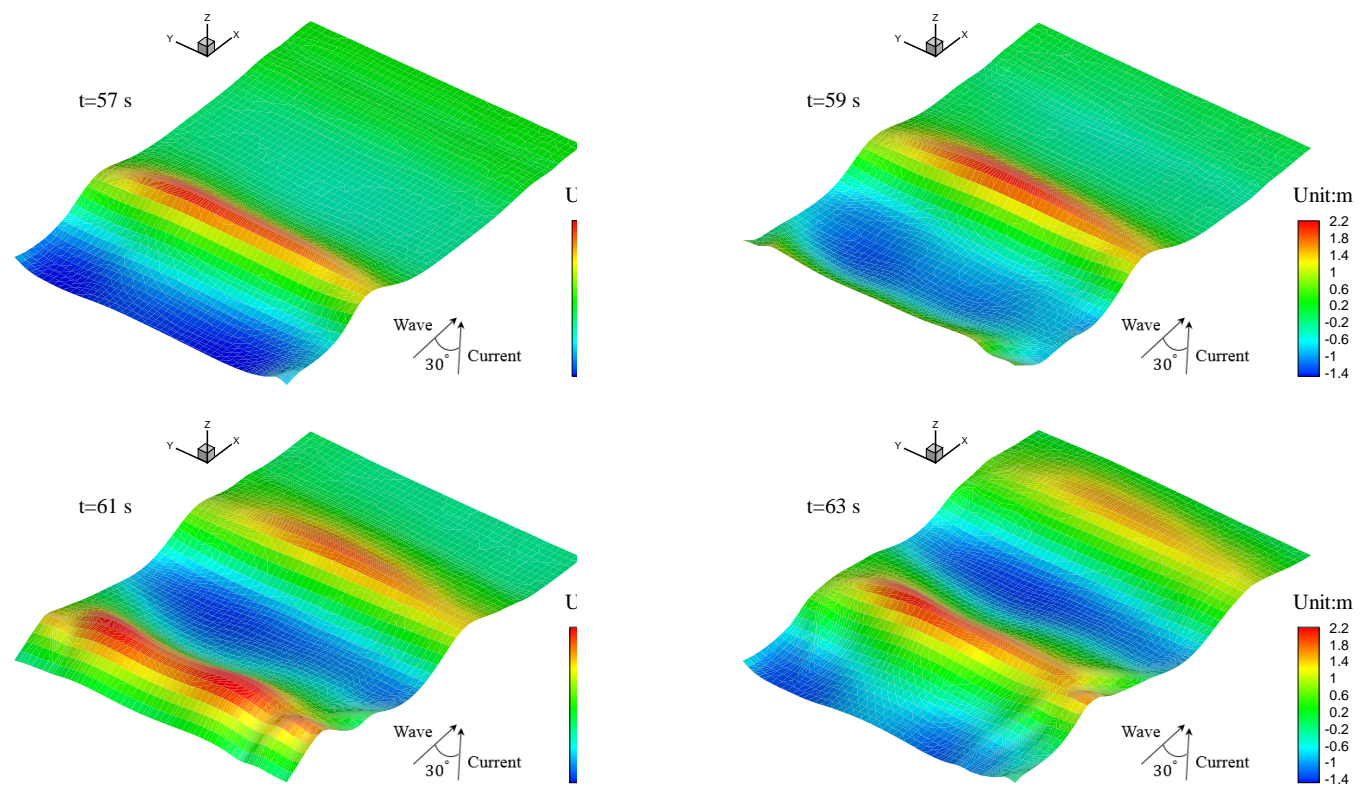

Fig. 7. Three-dimensional view of the interaction of focused wave group with ocean currents $\left(U_{c}=1\right.$ $\mathrm{m} / \mathrm{s}$ ) with an angle of $30^{\circ}$.

\subsection{Wave and seabed characteristics}

In general, the wave characteristics play an important role in the prediction of seabed stability around a buried pipeline [Jeng and Lin, 1999]. In particular, the wave height $\left(H_{w}\right)$ can directly affect the wave forces on the seabed, and the water depth $\left(d_{w}\right)$ can affect the pore-water pressure and effective stresses in the seabed by affecting the wavelength $\left(L_{w}\right)$. The above research was based on wave-only loading, and how the ocean currents affect the seabed response needs to be investigated through a series of parametric studies.

Figure 10 illustrates the influence of wave height $\left(H_{w}\right)$ on the relative difference in the pore-water pressure $\left(\left|\Delta \tilde{p}_{s}\right| / p_{0}\right)$ and the maximum amplitude of the pore-water pressure $\left(\left|\tilde{p}_{s}\right| / p_{0}\right)$. The figure clearly indicates that a positive relationship between $\left|\Delta \tilde{p}_{s}\right| / p_{0}$ and $H_{w}$. Noted that, the bottom of the pipe is considered when $\theta=270^{\circ}$ in this study. As shown in the figure, the $\left|\Delta \tilde{p}_{s}\right| / p_{0}$ at both ends (i.e. $\theta=180^{\circ}$ and $360^{\circ}$ ) increases significantly as the $H_{w}$ increases. However, the $\left|\Delta \tilde{p}_{s}\right| / p_{0}$ visibly increases as $H_{w}$ decreases along the vertical depth. After passing through the middle of the seabed, there is a positive relationship between $\left|\Delta \tilde{p}_{s}\right| / p_{0}$ and $H_{w}$ until it reaches the bottom of the seabed.

Figure 11 reveals the influence of water depth $\left(d_{w}\right)$ on the relative difference in the pore-pressure $\left(\left|\Delta \tilde{p}_{s}\right| / p_{0}\right)$ and the maximum amplitude of the pore-water pressure $\left(\left|\tilde{p}_{s}\right| / p_{0}\right)$. As shown in the figure, both $\left|\Delta \tilde{p}_{s}\right| / p_{0}$ and $\left|\tilde{p}_{s}\right| / p_{0}$ increase as the 


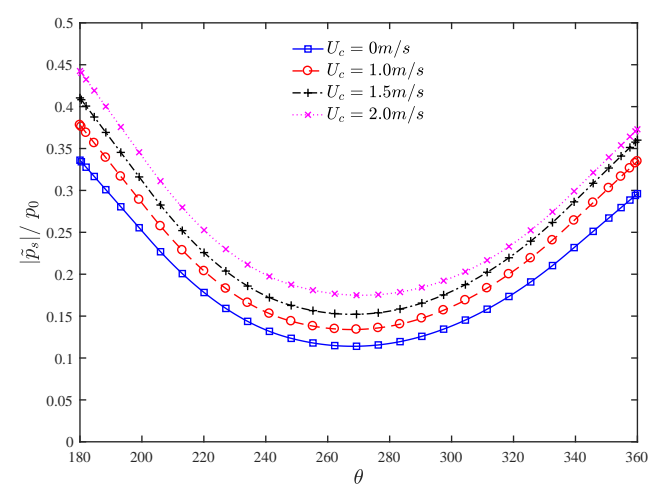

(a)

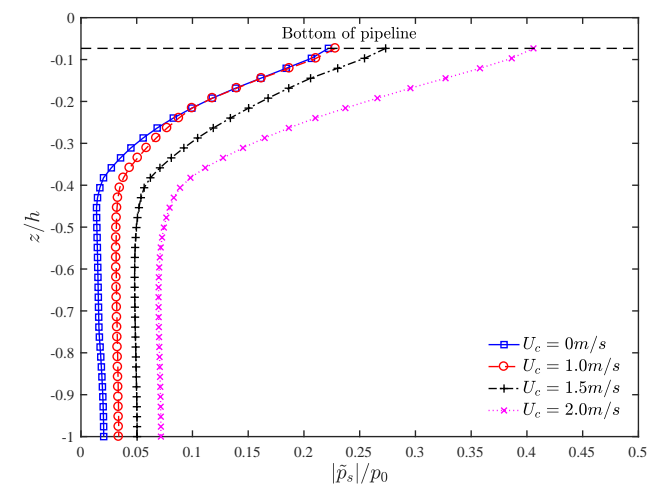

(c)

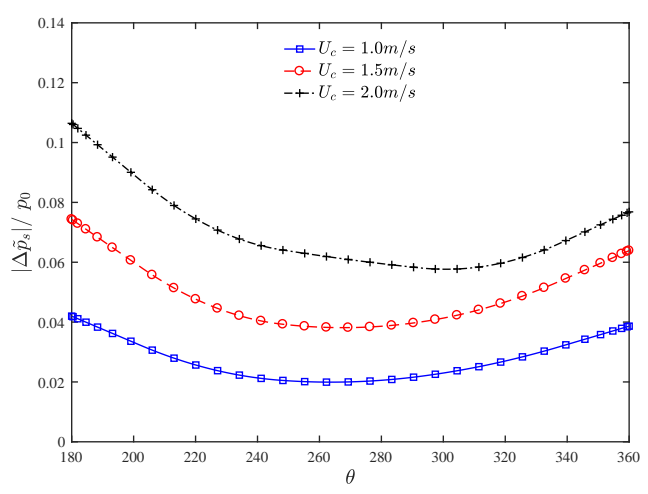

(b)

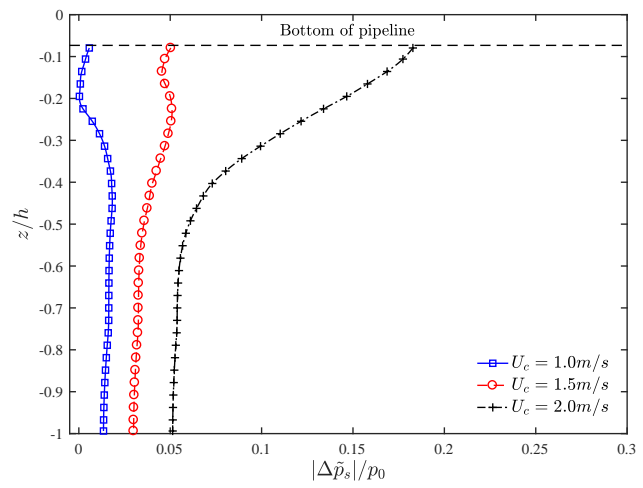

(d)

Fig. 8. Distributions of the maximum pore-water pressure $\left(\left|\tilde{p}_{s}\right| / p_{0}\right)$ and the relative difference in the pore-water pressure $\left(\left|\Delta \tilde{p}_{s}\right| / p_{0}\right)$ for various velocities of ocean currents $\left(U_{c}\right)$ : (a) \& (b) along the periphery of the pipeline; (c) \& (d) along the vertical line through the centre of the pipeline when $H_{w}=1.5 \mathrm{~m}, T_{w}=6 \mathrm{~s}, d_{w}=8 \mathrm{~m}, \alpha=30^{\circ}, S_{r}=0.992$ and $k_{s}=1.0 \times 10^{-3} \mathrm{~m} / \mathrm{s}$.

$d_{w}$ decreases. It is worth noting that $\left|\Delta \tilde{p}_{s}\right| / p_{0}$ continuously decreases along the periphery of the pipeline (i.e. from $\theta=180^{\circ}$ to $360^{\circ}$ ) when $d_{w}$ is $12 \mathrm{~m}$. Moreover, the vertical distribution of $\left|\Delta \tilde{p}_{s}\right| / p_{0}$ gradually decays, except for the case where $d_{w}$ is equal to $8 m$, in which $\left|\Delta \tilde{p}_{s}\right| / p_{0}$ decreasing initially and then increases before finally decreasing slowly until reaching the bottom.

In summary, the effect of the combined loads of waves and currents on the seabed response is more pronounced on the upstream side of the pipeline than on the downstream side with a large wave and in shallow water.

As reported in the literature [Jeng, 2003], soil permeability $\left(k_{s}\right)$ and the degree of saturation $\left(S_{r}\right)$ will significantly affect the wave-induced seabed response in a porous seabed. Nevertheless, the combined loads of non-linear waves and ocean 


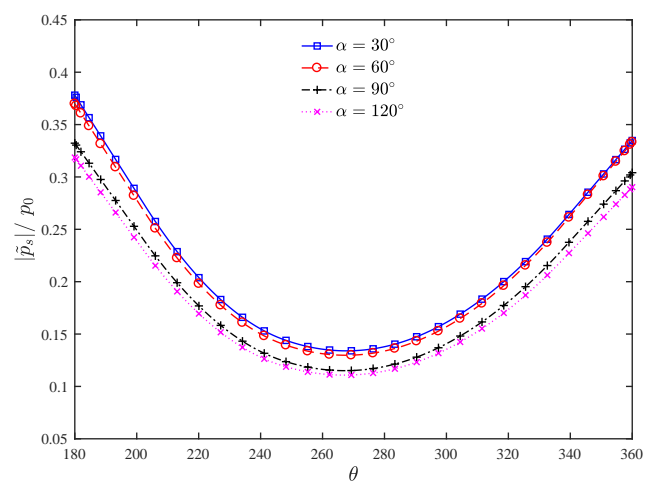

(a)

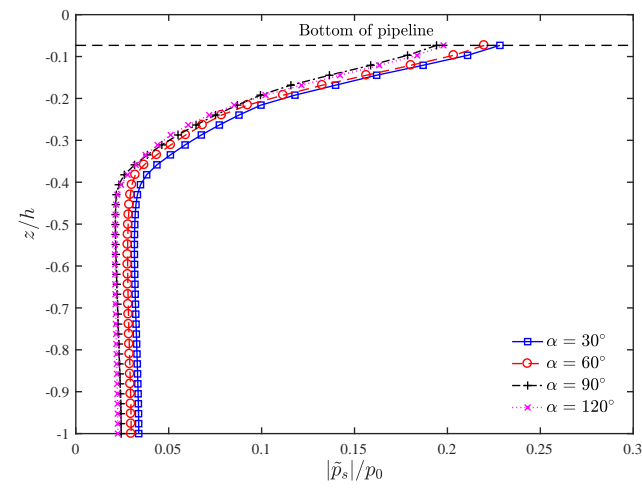

(b)

Fig. 9. Distributions of the maximum pore-water pressure $\left(\left|\tilde{p}_{s}\right| / p_{0}\right)$ for various interaction angles $(\alpha)$ of current: (a) along the periphery of the pipeline; (b) along the vertical line through the centre of the pipeline when $H_{w}=1.5 \mathrm{~m}, T_{w}=6 \mathrm{~s}, d_{w}=8 \mathrm{~m}, U_{c}=1 \mathrm{~m} / \mathrm{s}, S_{r}=0.992$ and $k_{s}=1.0 \times 10^{-3} \mathrm{~m} / \mathrm{s}$.

currents are also examined with soil permeability and the degree of saturation on the development of the maximum pore-water pressure $\left(\left|\tilde{p}_{s}\right| / p_{0}\right)$ and the relative difference in the pore-pressure $\left(\left|\Delta \tilde{p}_{s}\right| / p_{0}\right)$ in detail.

As illustrated in Figures 12 and 13, both $\left|\tilde{p}_{s}\right| / p_{0}$ and $\left|\Delta \tilde{p}_{s}\right| / p_{0}$ generally increase with an increase of $k_{s}$ and $S_{r}$ along the periphery of the pipeline. For various $k_{s}$ and $S_{r}$, a greater value of $\left|\Delta \tilde{p}_{s}\right| / p_{0}$ is observed in the upper layer of the seabed of unsaturated and denser sand. However, the variation trend will reverse in the specific region from $z / h=-0.3$ to the end of the bottom. Furthermore, greater value of $\left|\Delta \tilde{p}_{s}\right| / p_{0}$ is observed in the lower part of the porous seabed with a larger $k_{s}$ and $S_{r}$. We can conclude that the effect of the wave-current combination is more significant in the upper seabed with a smaller $k_{s}$ and $S_{r}$, while it is more significant in the lower region with a large $k_{s}$ and $S_{r}$. 


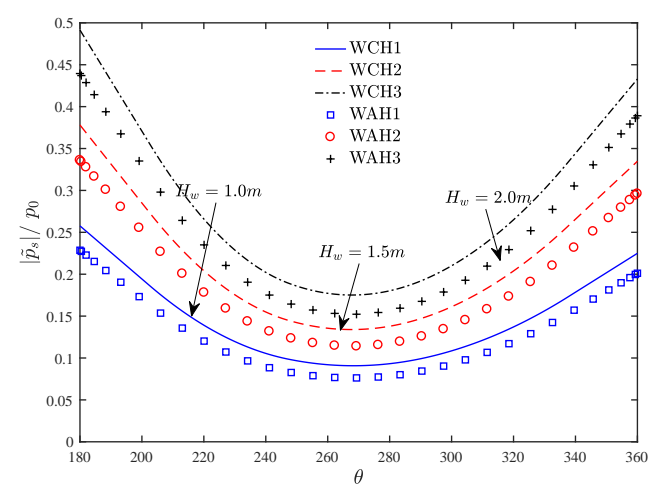

(a)

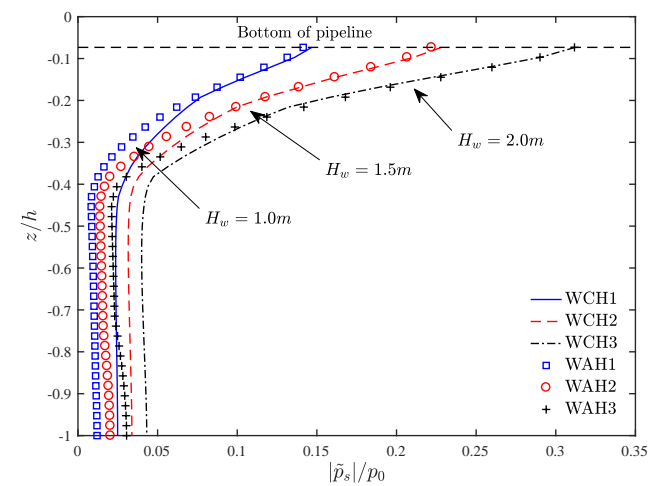

(c)

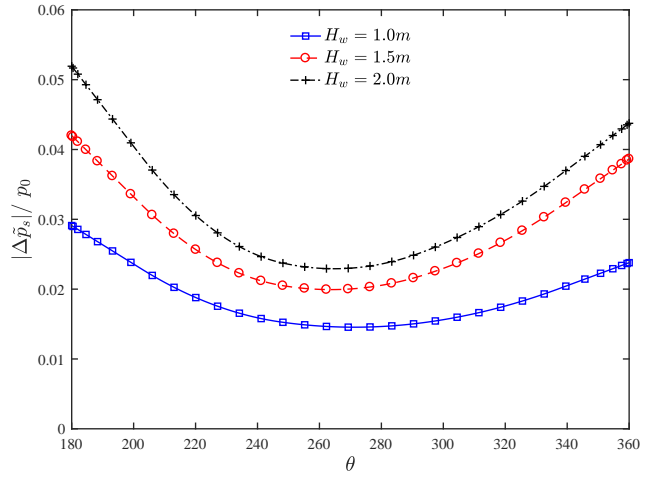

(b)

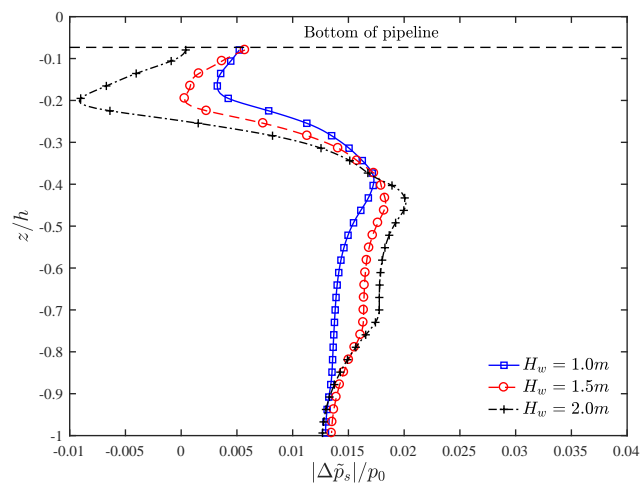

(d)

Fig. 10. Distributions of the maximum pore-water pressure $\left(\left|\tilde{p}_{s}\right| / p_{0}\right)$ and the relative difference in the pore-water pressure $\left(\left|\Delta \tilde{p}_{s}\right| / p_{0}\right)$ for various wave heights $\left(H_{w}\right)$ : (a) and (b) along the periphery of the pipeline; (c) and (d) along the vertical line through the centre of the pipeline when $T_{w}=6 \mathrm{~s}$, $d_{w}=8 \mathrm{~m}$ and $U_{c}=1 \mathrm{~m} / \mathrm{s}$ with $\alpha=30^{\circ}$.

\subsection{Liquefaction around a buried pipeline}

Generally speaking, liquefaction is considered as a kind of quicksand or a boiling action that is closely related to seepage flows and results from the increase in the pore-water pressure with decreasing effective stress [Jeng, 2013].

The criterion proposed by Zen and Yamazaki [1990] has been widely used as a first-hand approximation for the evaluation of wave-induced transient liquefaction in marine sediments and can be expressed in terms of initial stress status and waveinduced excess pore water pressure in the seabed foundation as:

$$
-\left(\gamma_{s}-\gamma_{w}\right) z \leq\left(\tilde{p}_{s}-p_{b 0}\right)
$$

where $\gamma_{s}$ is the saturated weight of the soil; $\gamma_{w}$ is the unit weight of water; $z$ is the 


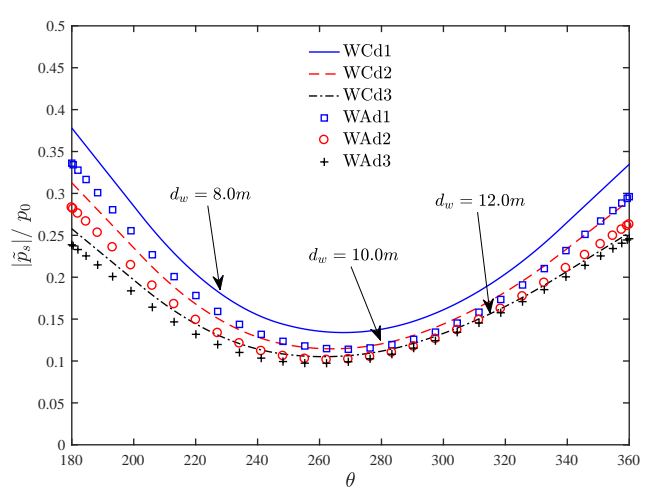

(a)

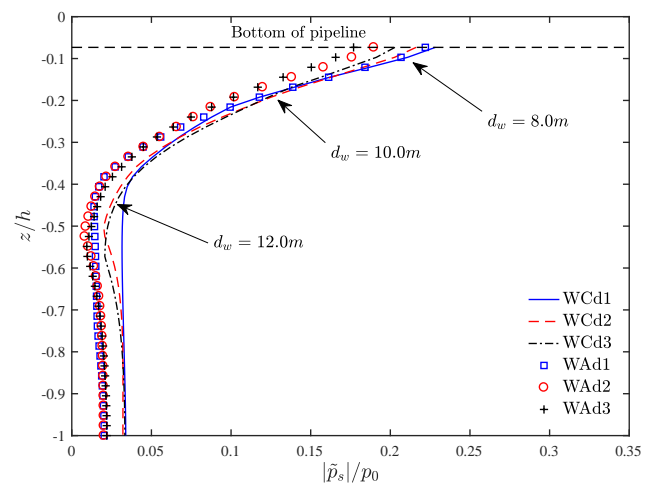

(c)

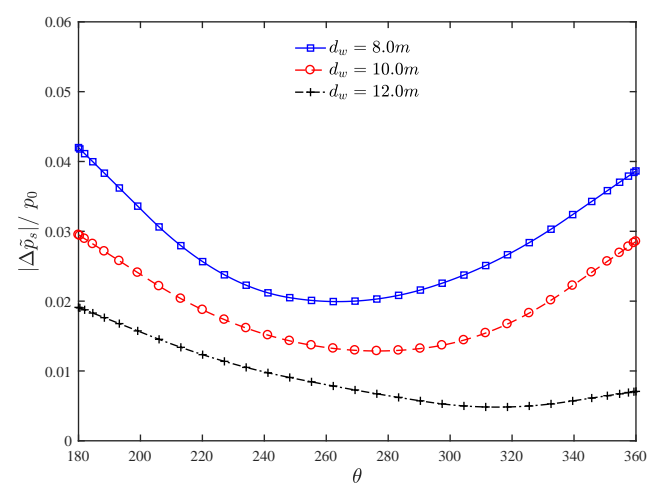

(b)

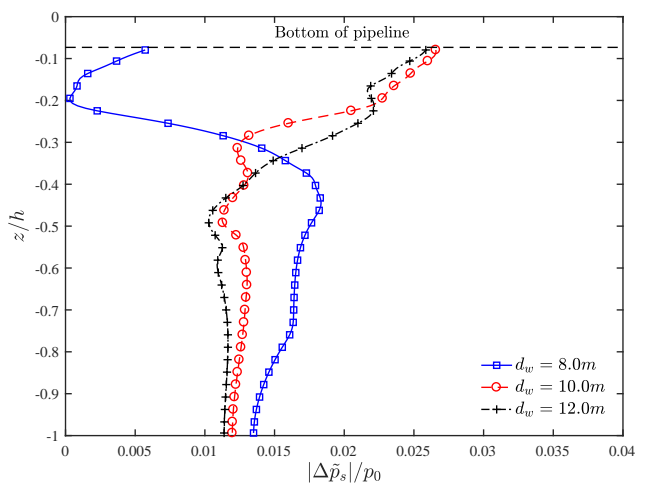

(d)

Fig. 11. Distributions of the maximum pore-water pressure $\left(\left|\tilde{p}_{s}\right| / p_{0}\right)$ and the relative difference in the pore-water pressure $\left(\left|\Delta \tilde{p}_{s}\right| / p_{0}\right)$ for various water depths $\left(d_{w}\right)$ : (a) and (b) along the periphery of the pipeline; (c) and (d) along the vertical line through the centre of the pipeline when $H_{w}=1.5$ $m, T_{w}=6 \mathrm{~s}$ and $U_{c}=1 \mathrm{~m} / \mathrm{s}$ with $\alpha=30^{\circ}$.

depth; $p_{b 0}$ is the wave-induced dynamic pressure acting on the seabed surface; $\tilde{p}_{s}$ is the pore-water pressure within the porous seabed. That is to say, liquefaction may occur once the net excess pore-water pressure becomes greater than the over-burden soil pressure.

Jeng [1997] further extended the above criterion into the 3-D situation by considering the average of the effective stress:

$$
-\frac{1}{3}\left(\gamma_{s}-\gamma_{w}\right)\left(1+2 K_{0}\right) z \leq \tilde{p}_{s}-p_{b 0}
$$

where $K_{0}$ is the lateral compression coefficient of the soil and the left-hand side of Eq. (23) represents the average effective geo-static stress.

The above criterion is only valid for cases without a marine structure. When 


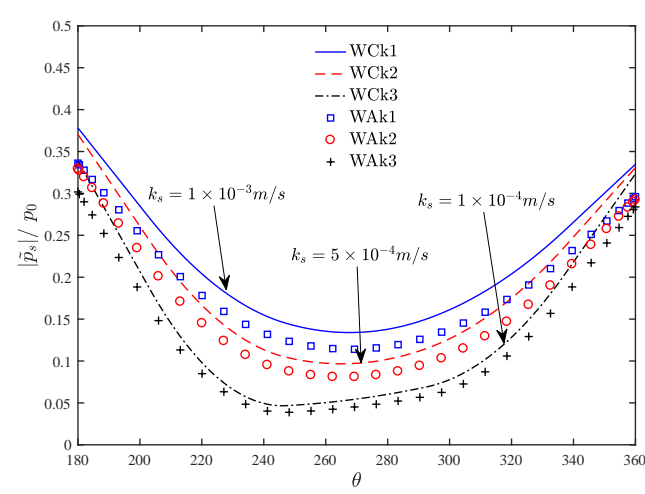

(a)

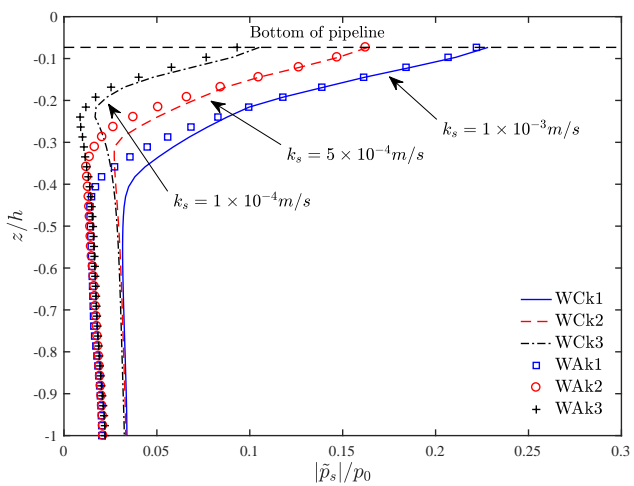

(c)

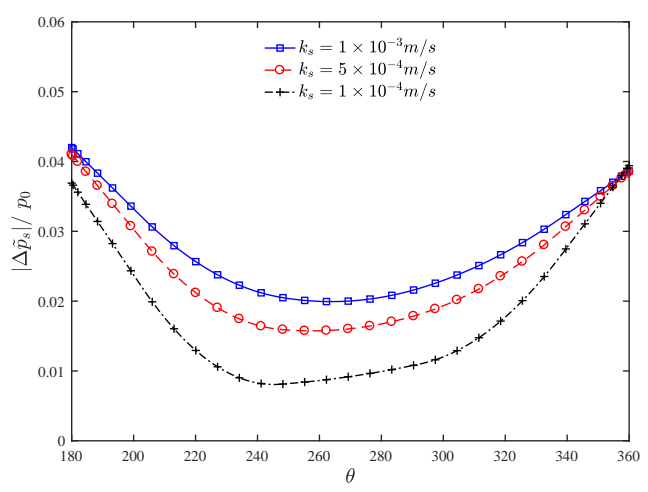

(b)

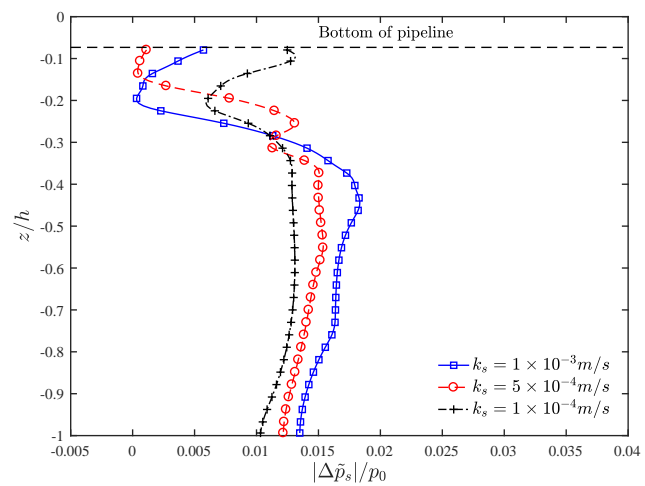

(d)

Fig. 12. Distributions of the maximum pore-water pressure $\left(\left|\tilde{p}_{s}\right| / p_{0}\right)$ and the relative difference in the pore-water pressure $\left(\left|\Delta \tilde{p}_{s}\right| / p_{0}\right)$ for various soil permeabilities $\left(k_{s}\right)$ : (a) and (b) along the periphery of the pipeline; (c) and (d) along the vertical line through the centre of the pipeline when $H_{w}=1.5 \mathrm{~m}, T_{w}=6 \mathrm{~s}, d_{w}=8 \mathrm{~m}$ and $U_{c}=1 \mathrm{~m} / \mathrm{s}$ with $\alpha=30^{\circ}$.

a marine structure is incorporated into the analysis, as discussed previously, the initial stress state condition is modified by the body forces of the structure through the consolidation process. Therefore, the modified liquefaction criterion in terms of the mean normal effective stress can be rewritten as Zhao et al. [2014]:

$$
\sigma_{0}^{\prime}=\frac{\sigma_{x 0}^{\prime}+\sigma_{y 0}^{\prime}+\sigma_{z 0}^{\prime}}{3} \leq \tilde{p}_{s}-p_{b 0}
$$

where $\sigma_{x 0}^{\prime}, \sigma_{y 0}^{\prime}$ and $\sigma_{z 0}^{\prime}$ are the horizontal and vertical components of effective stress, which comes from consolidation of the seabed under gravitational forces, including the self-gravity of the structure.

Based on the modified criterion mentioned above, the potential for wave-induced 


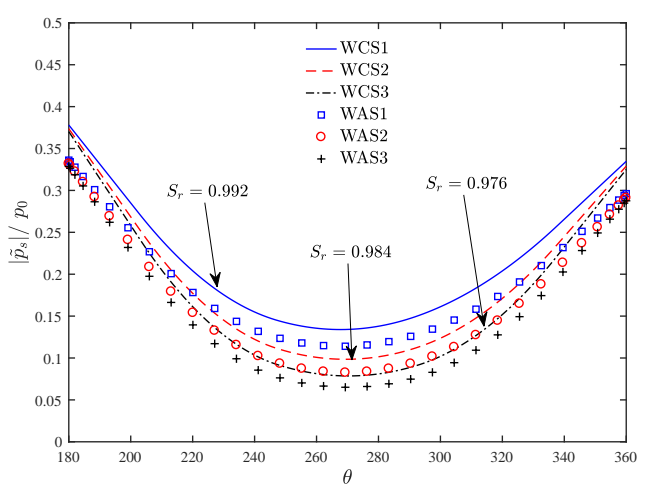

(a)

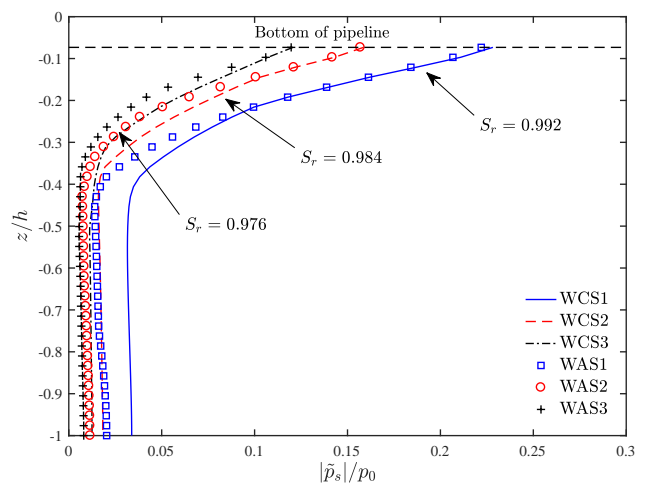

(c)

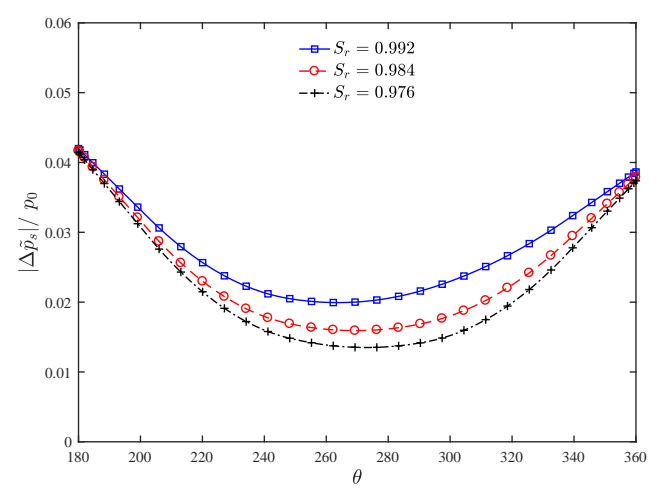

(b)

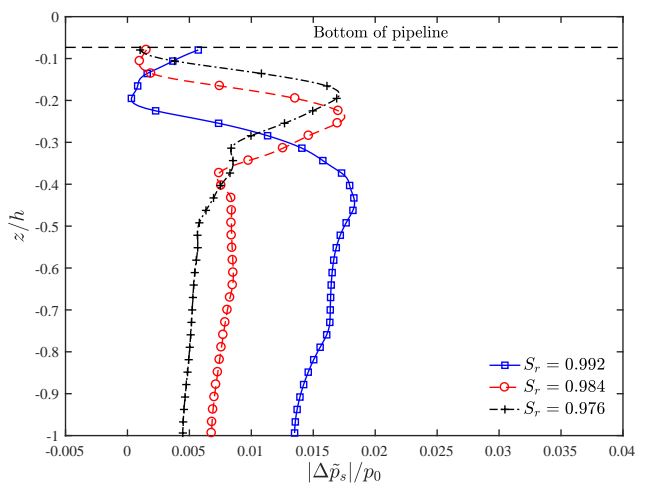

(d)

Fig. 13. Distributions of the maximum pore-water pressure $\left(\left|\tilde{p}_{s}\right| / p_{0}\right)$ and the relative difference in the pore-water pressure $\left(\left|\Delta \tilde{p}_{s}\right| / p_{0}\right)$ for various degrees of saturation $\left(k_{s}\right)$ : (a) and (b) along the periphery of the pipeline; (c) and (d) along the vertical line through the centre of the pipeline when $H_{w}=1.5 \mathrm{~m}, T_{w}=6 \mathrm{~s}, d_{w}=8 \mathrm{~m}$ and $U_{c}=1 \mathrm{~m} / \mathrm{s}$ with $\alpha=30^{\circ}$.

liquefaction around a submarine pipeline can be assessed using the developed model. As seen in Figure 14, the distribution of the liquefaction depth is quite different for various intersection angles $(\alpha)$ between the incident waves and oblique currents. Furthermore, the maximum liquefaction depth tends to occur in the region near the upstream zone of ocean currents because the waves that travel in the direction of the currents can increase the wave pressure at the seabed surface, which will further affect the pore-water pressure within the soil [Ye and Jeng, 2012]. Similarly, ocean currents that interact with the waves in the same direction can also increase the potential for liquefaction near the submarine pipeline with a smaller interaction angle.

Figure 15 illustrates the potential liquefaction zone near a pipeline for various 

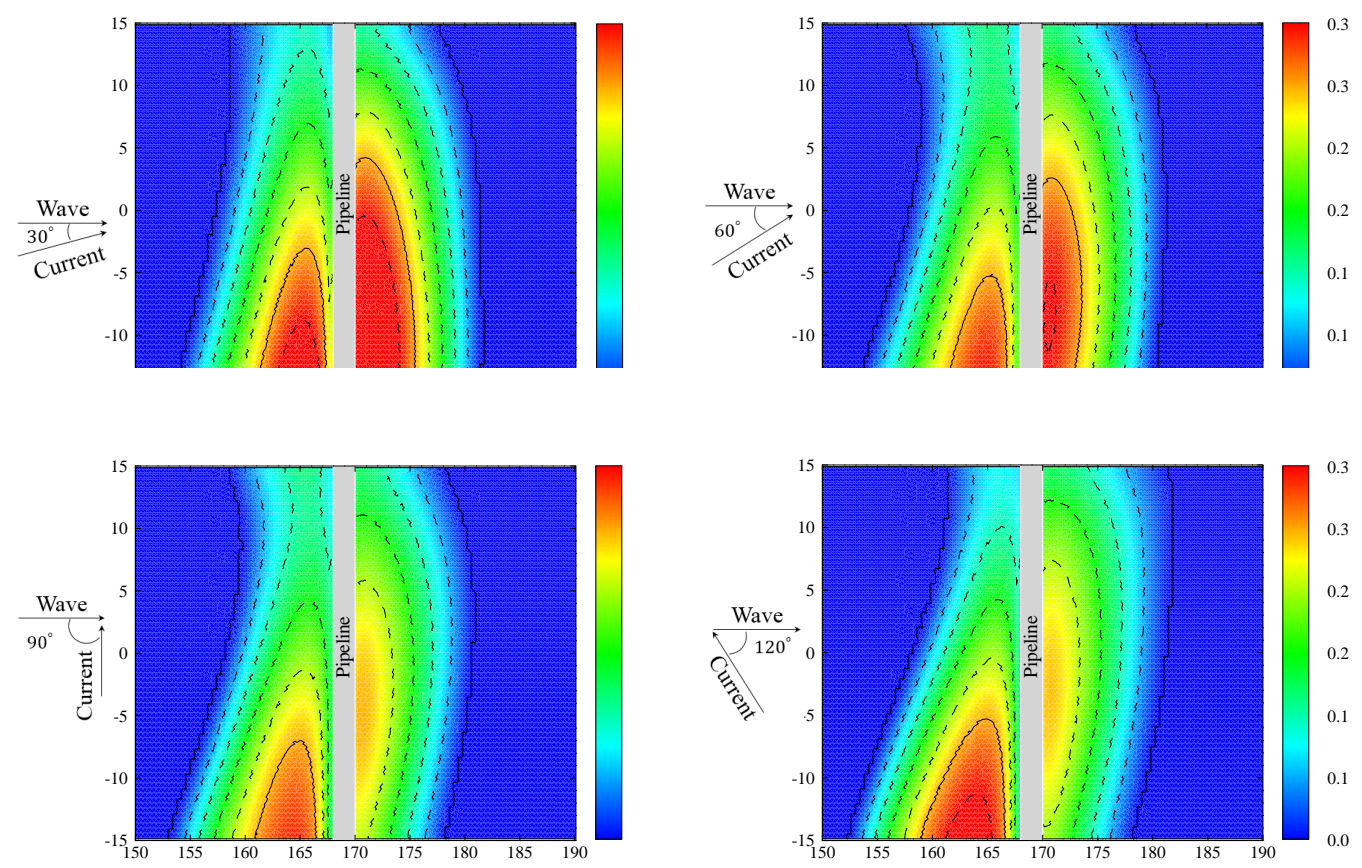

Fig. 14. Distribution of the liquefaction depth around a submarine pipeline for various interaction angles $(\alpha)$ of the current.

wave and soil properties. When investigating the effects of water depth, wave height and the degree of saturation on the potential liquefaction under the effect of ocean currents, the soil permeability is set to $1.0 \times 10^{-3} \mathrm{~m} / \mathrm{s}$, in which the soil is considered as coarse sand. The ocean current is equal to $1 \mathrm{~m} / \mathrm{s}$ and the interaction angle is $30^{\circ}$. As shown in the figure, the liquefaction depth has a negative relationship with water depth and the degree of saturation. Whereas the liquefaction depth increases as the wave height increases positively. However, this trend is not very sensitive because a larger soil permeability makes the pore-water pressure to dissipate easier. With decreasing soil permeability, the simulation results indicate that the liquefaction depth increases significantly. More specifically, soil liquefaction occurs in several areas near the bottom of the pipeline.

\subsection{Influence of pipeline configuration}

In this section, the effect of two other important parameters including the burial depth $(e)$ and pipe diameter $\left(D_{p}\right)$ on the distribution of relative difference of porewater pressure $\left(\left|\Delta \tilde{p}_{s}\right| / p_{0}\right)$ and the maximum pore-water pressure $\left(\left|\tilde{p}_{s}\right| / p_{0}\right)$ are further investigated. Figure 16 presents the wave-induced lee-wake vortex and liquefaction zones of four different burial depths below the pipeline over one wavelength. The red area around the submarine pipeline is the wave-current-induced liquefied 

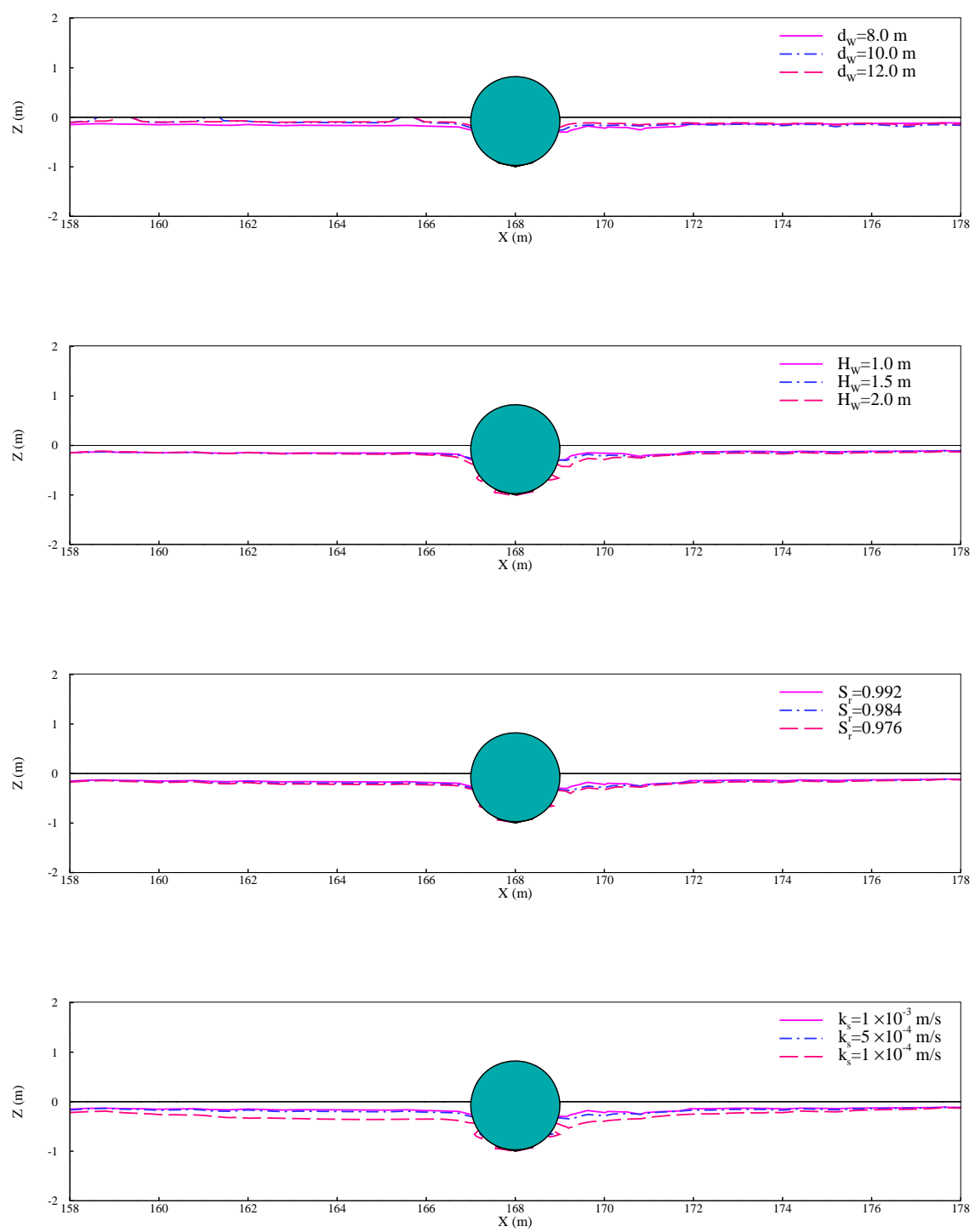

Fig. 15. Distribution of the liquefaction zone in the vicinity of a submarine pipeline for various values of (a) water depth, $d_{w}$; (b) wave height, $H_{w}$; (c) degree of saturation, $S_{r}$; (d) soil permeability, $k_{s}$ under combined wave and current loads when $U_{c}=1 \mathrm{~m} / \mathrm{s}$ with $\alpha=30^{\circ}$ and $D_{p}=2 \mathrm{~m}$.

zone. The length of the blue vector represents the amplitude of fluid velocity in each mesh cell. As shown in the figure, the buried depth of the pipeline can immediately alter the flow patterns in its neighbourhood in turn. Likewise, the appearance of a vortex may increase the possibility of the onset of liquefaction around the pipeline 

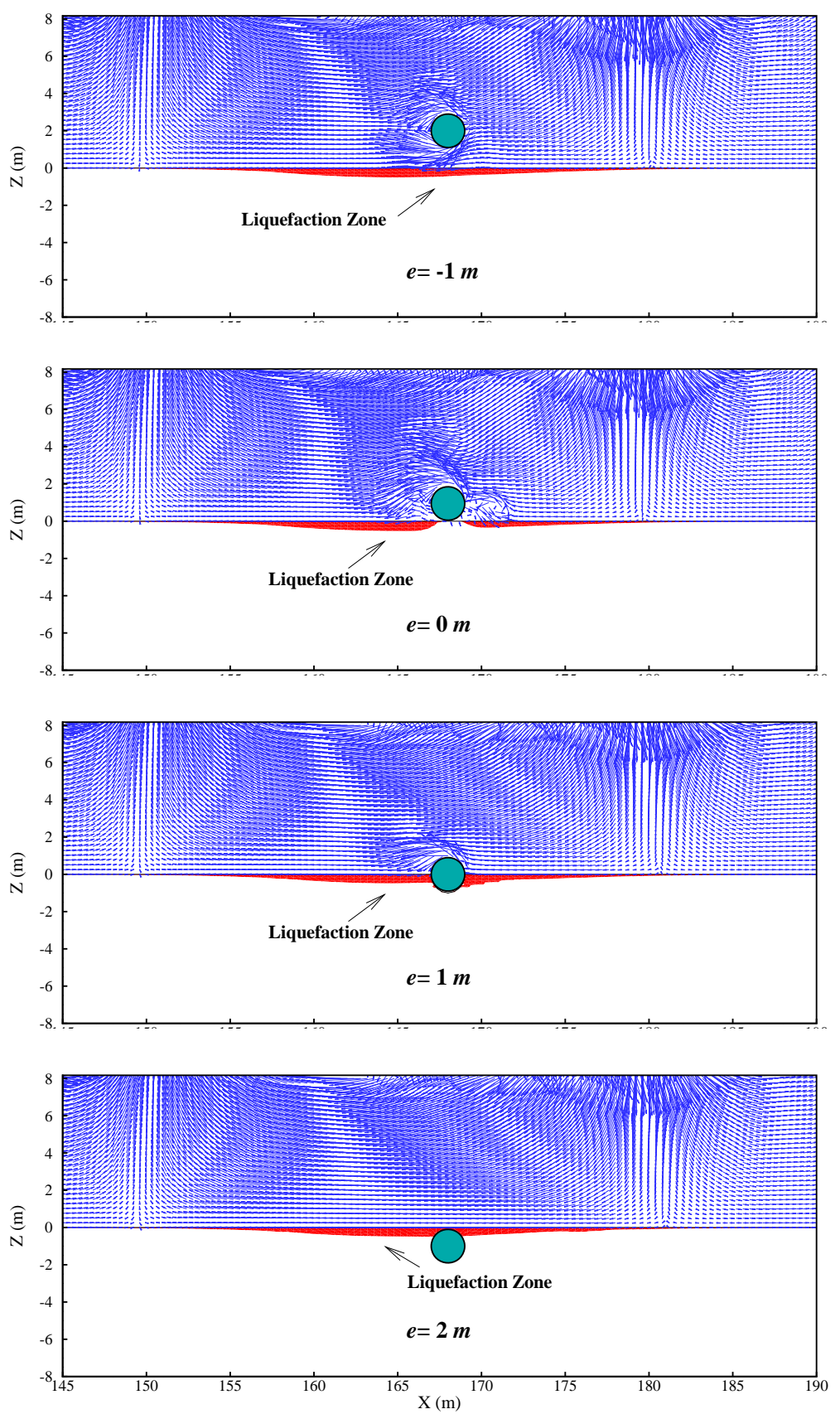

Fig. 16. Distribution of the instantaneous velocity fields and liquefaction zone in the vicinity of a submarine pipeline for various burial depths $(e)$ under combined wave and current loads when $H_{w}=1.5 \mathrm{~m}, T_{w}=6 \mathrm{~s}, d_{w}=8 \mathrm{~m}$ and $U_{c}=1 \mathrm{~m} / \mathrm{s}$ with $\alpha=30^{\circ}$. 


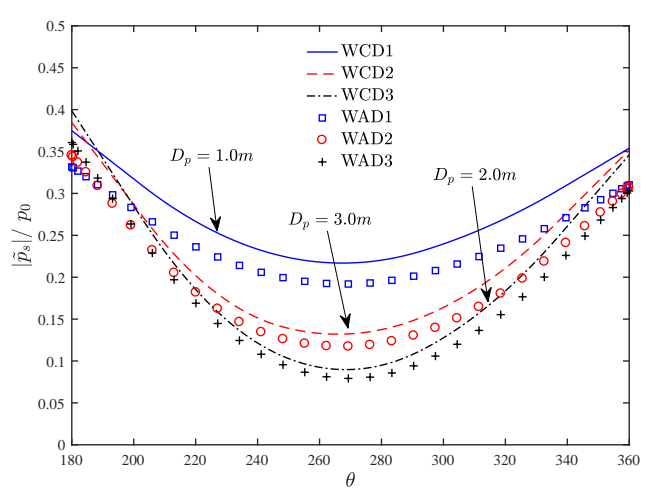

(a)

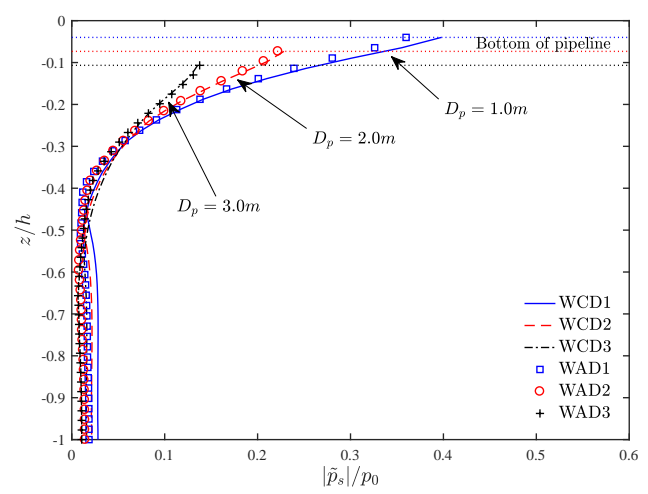

(c)

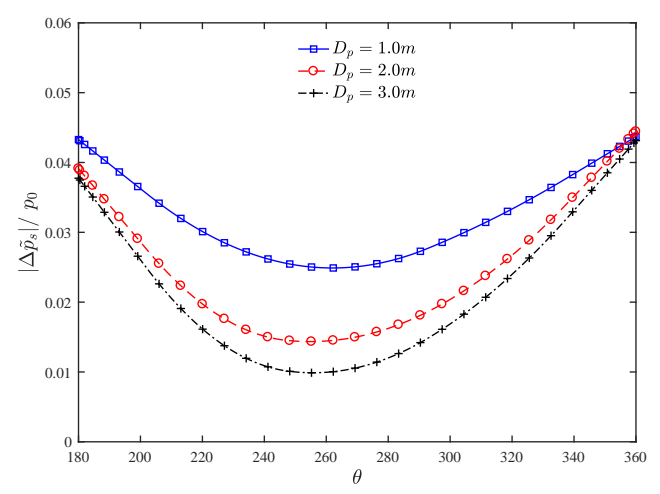

(b)

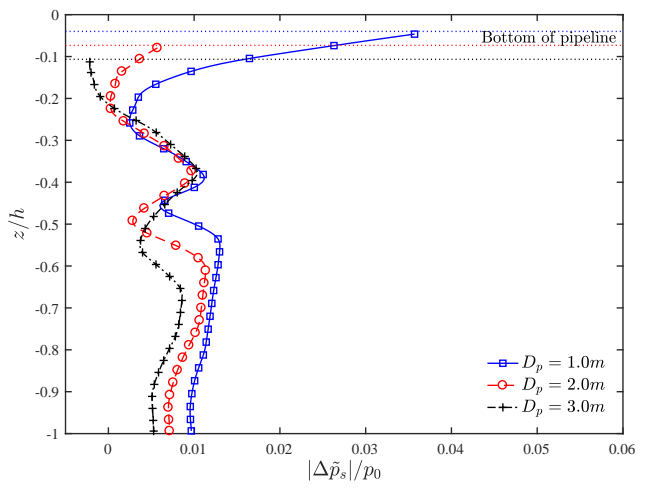

(d)

Fig. 17. Distributions of the maximum pore-water pressure $\left(\left|\tilde{p}_{s}\right| / p_{0}\right)$ and the relative difference in the pore water pressure $\left(\left|\Delta \tilde{p}_{s}\right| / p_{0}\right)$ for various pipe diameter $\left(D_{p}\right)$ : (a) and (b) along the periphery of the pipeline; (c) and (d) along the vertical line through the centre of the pipeline, when $H_{w}=1.5$ $m, T_{w}=6 \mathrm{~s}, d_{w}=8 \mathrm{~m}$ and $U_{c}=1 \mathrm{~m} / \mathrm{s}$ with $\alpha=30^{\circ}$.

because of the massive movement of the soil particles. Since the specific weight of the pipe is larger than that of the nearby soil grain, soil liquefaction is less likely to occur around the seabed foundation beneath the pipe. While the lateral zone easily becomes liquefied as a result of insufficient protective layers in cases with $e$ equal to 0 and $1 \mathrm{~m}$, respectively. In this situation, the submarine pipeline tends to sink into seabed if liquefaction occurs. Moreover, when the pipeline is completely covered by soil with $e=2 m$, no obvious liquefaction is observed at its bottom, and only a thin layer of soil on the upper surface becomes unstable, demonstrating that an offshore pipeline with sufficient embedding depth can avoid sinking or floating due to seabed liquefaction.

Another important parameter for pipeline configuration is the pipe diameter 


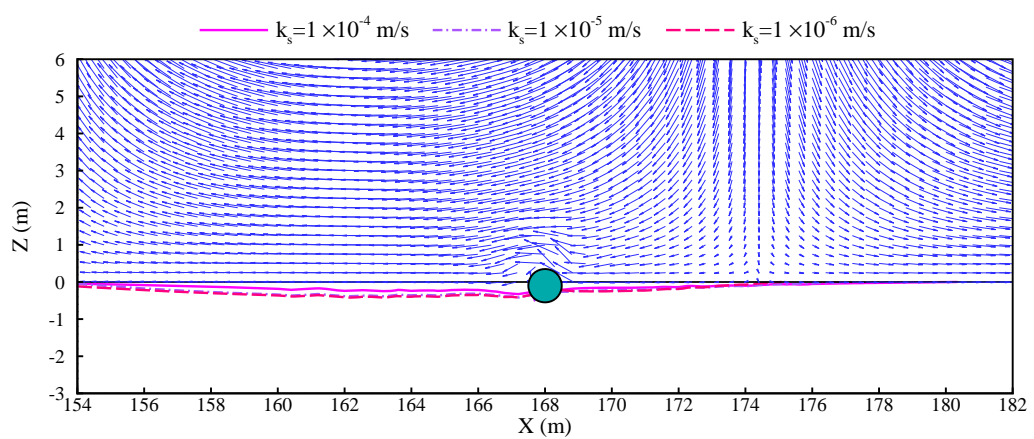

(a) $D_{p}=1 m$

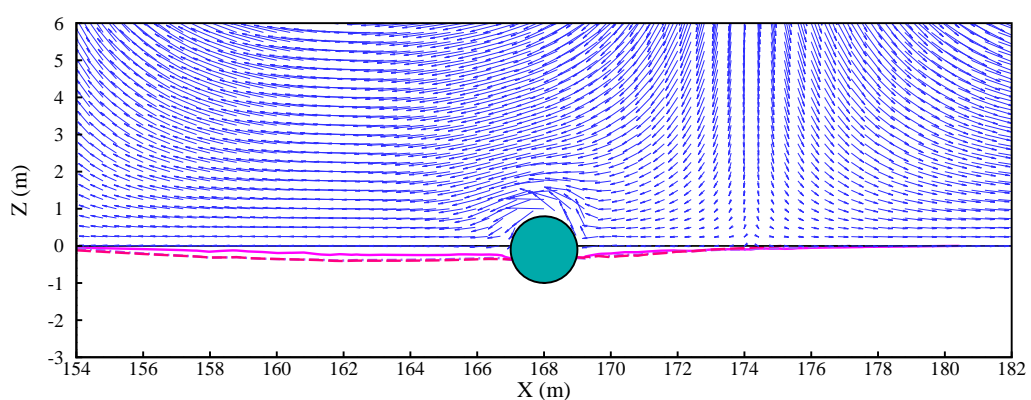

(a) $D_{p}=2 m$

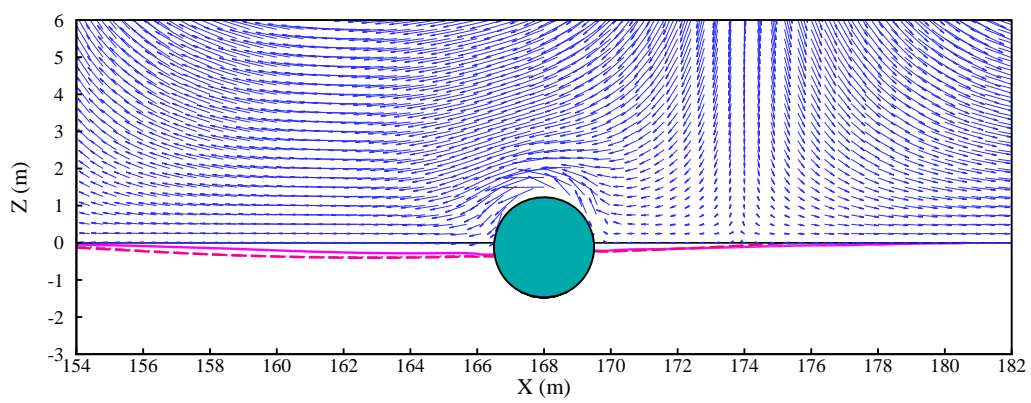

(a) $D_{p}=3 m$

Fig. 18. Distribution of the instantaneous velocity fields and pore-water pressure in the vicinity of a submarine pipeline for various diameters of pipe $\left(D_{p}\right)$ under the pure wave loads when $H_{w}=1.5$ $m, T_{w}=6 s$, and $d_{w}=8 m$. 


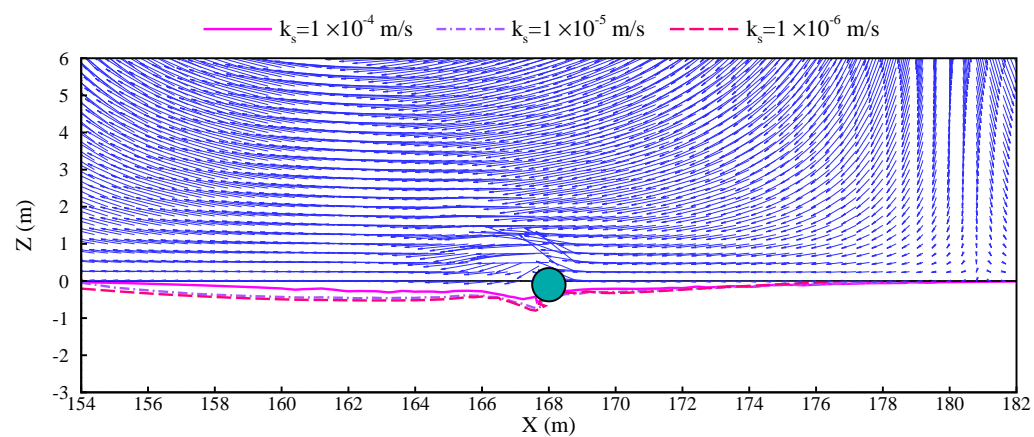

(a) $D_{p}=1 m$

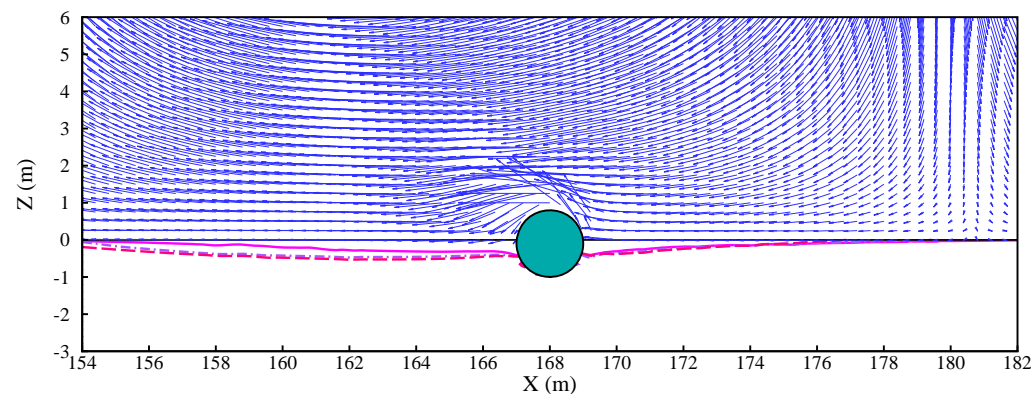

(a) $D_{p}=2 m$

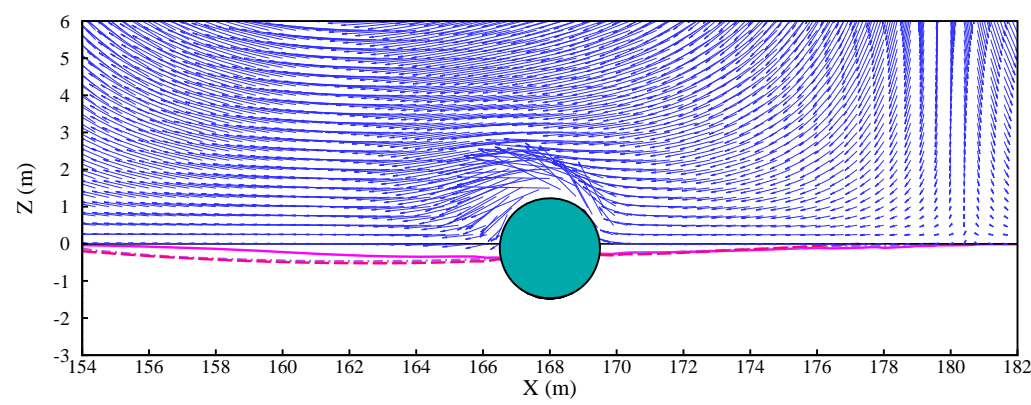

(a) $D_{p}=3 m$

Fig. 19. Distribution of the instantaneous velocity fields and pore-water pressure in the vicinity of a submarine pipeline for various diameters of pipe $\left(D_{p}\right)$ under combined wave and current loads when $H_{w}=1.5 \mathrm{~m}, T_{w}=6 \mathrm{~s}, d_{w}=8 \mathrm{~m}$ and $U_{c}=1 \mathrm{~m} / \mathrm{s}$ with $\alpha=30^{\circ}$.

${ }_{538}$ the periphery of the pipeline appears to be symmetrical with $D_{p}=1 \mathrm{~m}$, which reflects 
that a uniform distribution of pore-water pressure is generated near a submarine pipeline when smaller diameters. This can be explained by the fact that the porewater pressure generated by the waves and ocean currents is quickly transmitted along the smaller pipe surface and thus the presence of the pipeline does not impede the cycling variation of the pore-water pressure within the soil.

As illustrated in Figure 18, a larger eddy current appears on the upper surface of the pipe in the case where there is no influence of the oblique currents. Moreover, this phenomenon becomes more apparent as the pipe diameter $\left(D_{p}\right)$ increases. The eddy currents formed on the upstream and downstream sides of the pipe are one of the main factors that transport sand from the pipe foundation, causing the onset of scour around the pipeline [Mao, 1986]. It needs to be clarified that the self-weight of the pipe remains unchanged even if the diameter of the pipe increases. As shown in the figure, the fluid velocity near the pipe surface is larger than that in other zones. With regard to the wave-induced soil momentary liquefaction, the liquefaction depth on the upstream side of the pipeline is greater than that on the downstream side. As $D_{p}$ increases, the influence of $k_{s}$ on soil momentary liquefaction becomes weak. This can be attributed to the pipe with a larger $D_{p}$ increasing the effective stress between the soil particles, thus providing higher stability to the seabed foundation.

By comparison, a more intense interaction among the fluid, submarine pipeline and seabed can be observed from Figure 19 in the presence of ocean currents. As shown in the figure, under the co-action of oblique ocean currents, the fluid velocity near the pipe surface becomes more intense, and the affected region also becomes larger as the pipe diameter increases. In terms of the momentary liquefaction, the bottom of the pipe with $D_{p}=1 \mathrm{~m}$ becomes unstable when the $k_{s}$ is smaller than $1.0 \times 10^{-4} \mathrm{~m} / \mathrm{s}$. As a result, the submarine pipeline will sink into the seaside since the specific weight of the pipeline is greater than that of the water and soil particles. Similarly, a submarine pipeline with a larger $D_{p}$ can still stabilise its nearby seabed foundation, even under the loads of ocean currents. However, the numerical results show that the presence of currents can increase the maximum liquefaction depth. In that case, the oblique ocean currents can not only induce a larger amplitude of porewater pressure in the vicinity of the submarine pipeline, but also directly increase the hydrodynamic pressure on the seabed surface. The increase in the pressure gradient between the seabed surface and porous seabed further increases the potential of liquefaction. Hence, it is necessary to consider all effects to protect the pipeline from the momentary liquefaction threat when the effects of ocean currents are nonnegligible for the design of submarine pipeline.

\section{Conclusions}

In this study, a 3-D integrated model is developed to investigate the interaction between the wave, current, seabed and submarine pipeline. In the present numerical model, the soil model is developed using the FVM method by solving the classical Biot's consolidation equation; the wave model is simulated by solving the Navier- 
Stokes equation under the framework of the FVM method. The developed model was validated by comparison with a series of laboratory experiments. Based on the numerical results, the following conclusions can be drawn:

(1) Despite there being no available 3-D experiment involving wave-pipeline-seabed interactions for validation, a comprehensive comparison between the present numerical model and the 2-D experimental data was conducted. The comparison indicates that the present model is reliable for the evaluation of wave-induced transient pore-water pressure in the vicinity of a submarine pipeline.

(2) The flow obliquity $(\alpha)$ between the incident waves and the ocean currents has a non-negligible effect on the instantaneous pore-water pressure around the submarine pipeline. The numerical results show that the instantaneous porewater pressure around the pipeline increases with decreasing flow obliquity; such influence can significantly increase with the increasing current velocity $\left(U_{c}\right)$. Moreover, the liquefaction zone is more easily observed near the inlet of the ocean currents.

(3) The maximum pore-water pressure $\left(\left|\tilde{p}_{s}\right| / p_{0}\right)$ and the relative difference in the pore-water pressure $\left(\left|\Delta \tilde{p}_{s}\right| / p_{0}\right)$ can increase to a large value with high soil permeability $\left(k_{s}\right)$ and degree of saturation $\left(S_{r}\right)$ subjected to the loads induced by larger wave height $\left(H_{w}\right)$ in shallow water depth $\left(d_{w}\right)$. With regards to the liquefaction depth, it decreases with increasing $d_{w}, k_{s}$ and $S_{r}$, but increases as $H_{w}$ increases. By comparison, the $k_{s}$ has a much more obvious impact than the other parameters.

(4) A smaller pipe diameter $\left(D_{p}\right)$ can enlarge the amplitude of $\left|\tilde{p}_{s}\right| / p_{0}$ and $\left|\Delta \tilde{p}_{s}\right| / p_{0}$. In such cases, the presence of the ocean current can increase the liquefaction potential within the soil around the submarine pipeline. Whereas, a pipeline with a lower value of burial depth $(e)$ can easily induce a non-negligible vortex at its lateral sides. This can notably increase the possibility of the onset of scour around the submarine pipeline, whereas the maximum liquefaction depth can decrease with increasing burial depth.

(5) It is vital to evaluate the onset of scour around the pipelines, which is generally related to the seepage flow in the sandy seabed driven by the pressure difference between the upstream and the downstream sides of pipe. The present model captures a larger region with stronger vortex along the pipe surface. The vortex may transport the soil particles away from pipe's lateral ends and inevitably generate a scour hole. Hence, the issues of the onset of scour needs to be addressed in the future.

\section{Acknowledgements}

The authors gratefully acknowledge the support of the Griffith University Research Service Team and the use of the High Performance Computing Cluster Gowonda to complete this research. The first author is thankful for the support of the Grif- 
Table 3. Wave characteristics for WSPI model validation.

\begin{tabular}{ccccc}
\hline Experiments/Characteristics & $H_{w}(m)$ & $T_{w}(s)$ & $d_{w}(m)$ & $U_{c}(m / s)$ \\
\hline \multirow{2}{*}{ Turcotte et al. $[1984]$} & 0.0524 & 0.9 & 0.533 & {$[-]$} \\
& 0.143 & 1.75 & 0.533 & {$[-]$} \\
& 0.0302 & 2.3 & 0.533 & {$[-]$} \\
\hline Umeyama $[2011]$ & 0.0091 & 1.0 & 0.3 & -0.08 \\
& 0.0202 & 1.0 & 0.3 & -0.08 \\
Mattioli et al. $[2012]$ & 0.0309 & 1.0 & 0.3 & -0.08 \\
\hline Liu et al. $[2015]$ & 0.1 & 2.0 & 0.3 & {$[-]$} \\
\hline
\end{tabular}

Table 4. Soil properties for the WSPI model validation.

\begin{tabular}{cccccc}
\hline Experiments/Characteristics & $k_{s}(\mathrm{~m} / \mathrm{s})$ & $G_{s}\left(\mathrm{~N} / \mathrm{m}^{2}\right)$ & $\mu_{s}$ & $n_{s}$ & $S_{r}$ \\
\hline Turcotte et al. $[1984]$ & $1.1 \times 10^{-3}$ & $6.4 \times 10^{5}$ & 0.33 & 0.42 & 0.95 \\
\hline \multirow{2}{*}{ Liu et al. $[2015]$} & $1.8 \times 10^{-4}$ & $1.27 \times 10^{7}$ & 0.3 & 0.425 & 0.996 \\
& $1.8 \times 10^{-4}$ & $1.27 \times 10^{7}$ & 0.3 & 0.425 & 0.951 \\
\hline
\end{tabular}

fith University International Postgraduate Research Scholarship and the Griffith University Postgraduate Research Scholarship.

\section{Appendix: Model validations}

The present FVM model was systematically validated using five sets of published laboratory experimental results available in the literature. The comparison with Sun et al. [2018]'s laboratory experiment is given in section 2, while the remaining four sets of validations are provided in detail below. Note that the wave and soil parameters considered in the numerical simulations for the verification are the same as those used in the laboratory experiments otherwise specified.

Configurations of the experimental set-up for Umeyama [2011], Mattioli et al. [2012] and Turcotte et al. [1984] are depicted in Figure 20. The wave parameters for the experiments [Turcotte et al., 1984; Umeyama, 2011; Mattioli et al., 2012; Liu et al., 2015] are given in Table 3, while the soil characteristics for experiments [Turcotte et al., 1984; Liu et al., 2015] are listed in Table 4

\section{A1 Comparison of the RANS solver and Umeyama [2011]'s laboratory measurements of a regular wave in conjunction with a uniform current travelling over a rigid bottom}

Umeyama [2011] conducted a series of experiments to study surface water waves propagating with or without a current at constant water depth. The experiment 


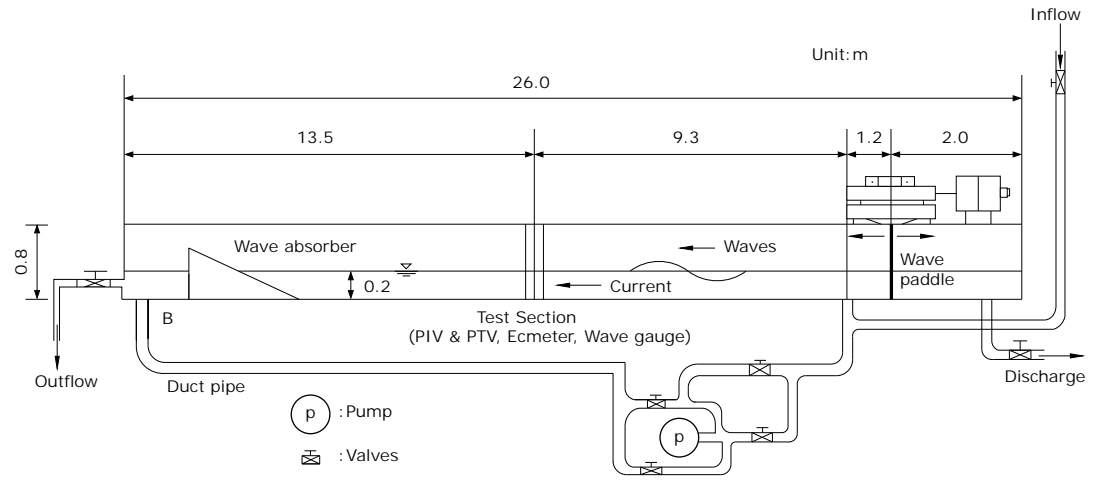

(a)

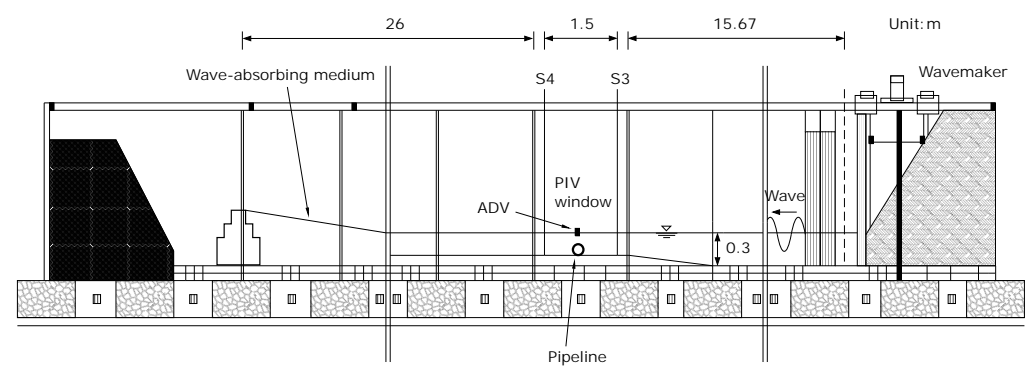

(b)

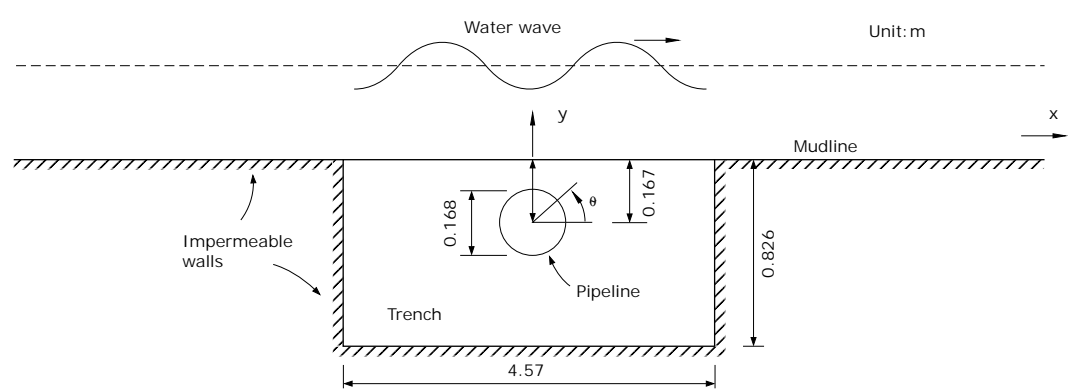

(c)

Fig. 20. Experimental set-up of previous wave flume tests for the validation of the present FVM model. (a) Umeyama [2011]'s experiment for the wave-current interaction over a rigid bottom; (b) Mattioli et al. [2012]'s laboratory investigation of the near-bed hydrodynamic interaction around a submarine pipeline; (c) Turcotte et al. [1984]'s experiment for the wave interaction with a trenched pipeline. 
was carried out in a recirculating wave tank that was $25 \mathrm{~m}$ long, $0.7 \mathrm{~m}$ wide, and $1.0 \mathrm{~m}$ deep. As illustrated in Figure 20(a), a piston-type wave-maker was placed at one end, and a wave absorber was installed at the other end. A pipe under the wave tank was used to recirculate the water flow, generating a steady following current with a depth-averaged velocity of $U_{0}=0.08 \mathrm{~m} / \mathrm{s}$. During all the tests in the wave tank, the water depth $(d)$ was $0.3 \mathrm{~m}$ and the wave period $(T)$ was $1.0 \mathrm{~s}$. Tests W1, $\mathrm{W} 2$ and W3 were for the waves without the presence of the following current, and their wave heights were $0.0103 \mathrm{~m}, 0.0234 \mathrm{~m}$ and $0.0361 \mathrm{~m}$, respectively. Tests $\mathrm{WC} 1$, $\mathrm{WC} 2$ and $\mathrm{WC} 3$ were the waves of $\mathrm{W} 1, \mathrm{~W} 2$ and $\mathrm{W} 3$ superimposed on the following current, respectively. The PIV measurement of horizontal velocity profiles in test WC1, WC2 and WC3 were used in the validation of the developed hydrodynamic model for the wave-current interaction without porous structures. Details about the laboratory measurements can be found in Umeyama [2011].

Figure 21 displays the time histories of the surface elevation for three cases with different wave heights. As shown in the figure, the results of the present model agree well with the experimental free surface time series. Figure 22 shows the simulated and measured horizontal velocity profiles at various phase values involved in the wave-current interactions. For all three cases, the simulated velocity data appears to be in reasonable accord with those obtained by the PIV measurement in the wave tank. The velocity profile is significantly affected by the surface wave motion. An upward-directed velocity gradient can be observed when the wave trough arrives, whereas the velocity increases significantly when the wave crest superimposes the current.

\section{A2 Comparison with Mattioli et al. [2012]'s laboratory investigation of the near-bed dynamic interaction between a regular wave and the submarine pipeline}

Mattioli et al. [2012] carried out sets of experiments to investigate the near-bed dynamics around a submarine pipeline lying on different types of seabed. The experiments at the basis of their study were performed in a wave flume that was 50 $m$ long, $1.3 m$ high and $1 m$ wide as shown in Figure 20(b). The regular wave was generated by a piston-type wave-maker and propagated toward the model section, which was $1.5 \mathrm{~m}$ long and placed approximately $10 \mathrm{~m}$ seaward of the porous bed and about $15 \mathrm{~m}$ shoreward of the generation system. Within the model section, a plexiglass pipe of $5 \mathrm{~cm}$ in diameter and $1 \mathrm{~m}$ in length was fastened to the wall of the flume, which was normal to the wave direction with an initial embedment $e / D=0$. Also, four wave gauges were used to measure the variation of the water surface during the experimental process. In particular, two of them, (i.e. S3 and S4) were placed at the seaward and shoreward end of the model section separately. In the experiments, the local water level $(h)$ was fixed at $0.3 \mathrm{~m}$. Other than that, the wave height $H$ was $0.1 \mathrm{~m}$ and the wave period ( $T$ was $2 s$ (i.e., $K C=13.67, R_{e}=0.427$ and $\left.U_{r}=38.93\right)$ for capturing the best description of both the flow and sand parti- 


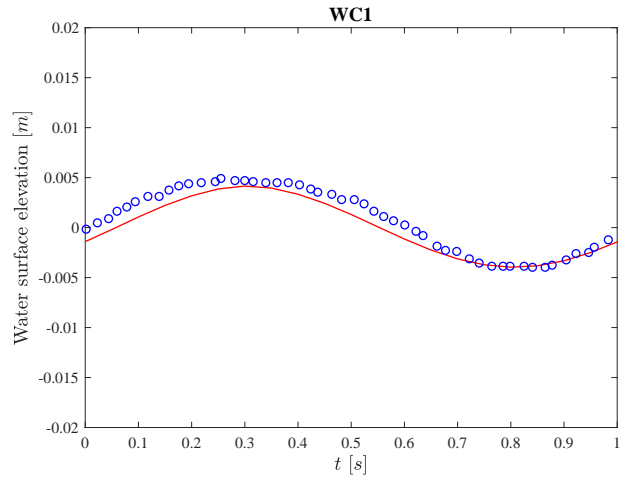

(a)

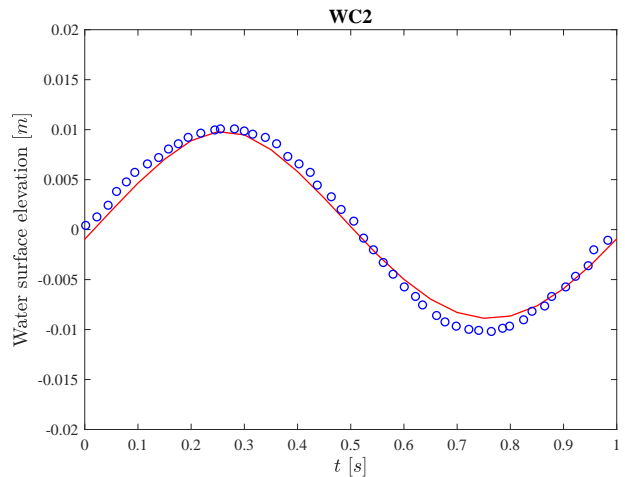

(b)

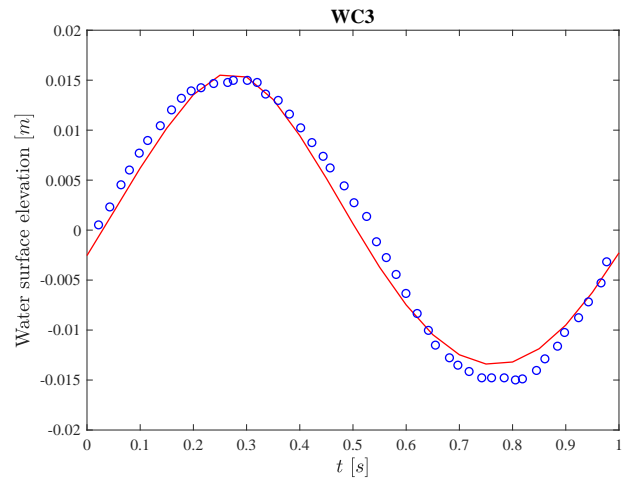

(c)

Fig. 21. Validation of free surface elevation for wave-current cases against experimental data [Umeyama, 2011]. Note: $z=0$ denotes the mean water level in the experiments.

cles motion. Meanwhile, the PTV measurements were used to characterise the flow in the surroundings of the submarine pipeline together with an Acoustic Doppler Velocimeter (ADV) for calibration and validation. As for the bottom of the flume, it was made of well-sorted sand with a mean diameter $\left(D_{50}\right)$ of $0.6 \mathrm{~mm}$ which can be considered as an erodible seabed.

Figure 23 shows the vertical distribution of the dimensionless horizontal fluid velocity $\left(u^{*}\right)$ through the centre of the pipeline $(z / D)$ for different wave phases from $0^{\circ}$ to $180^{\circ}$ with an increment of $45^{\circ}$. The dimensionless velocity $\left(u^{*}\right)$ is equal to $u /(H / T)$, and $D$ is the diameter of the submarine pipeline. Overall, the numerical results agree well with the experimental data of Mattioli et al. [2012]. 
(a)
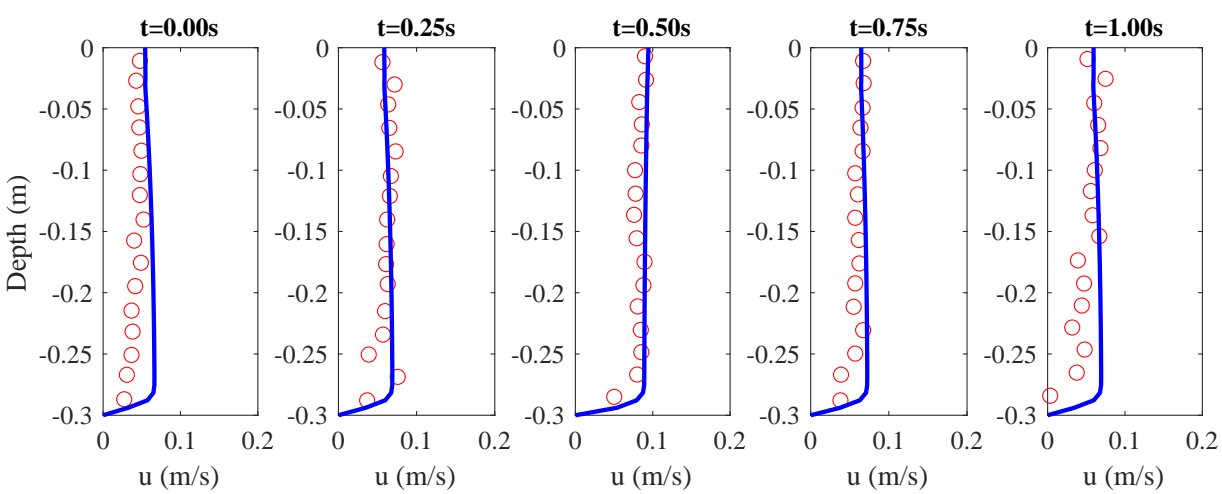

(b)
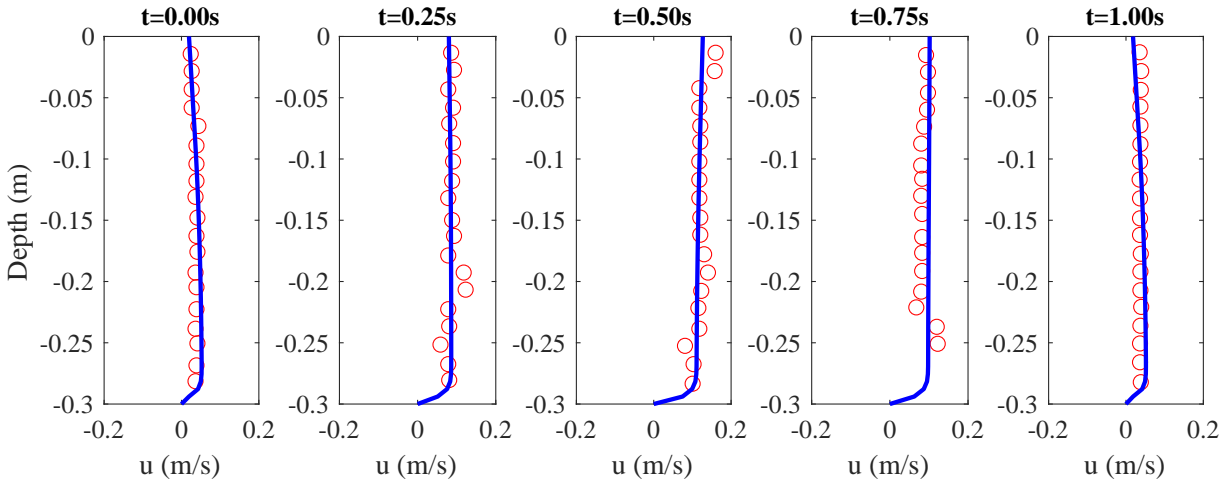

(c)
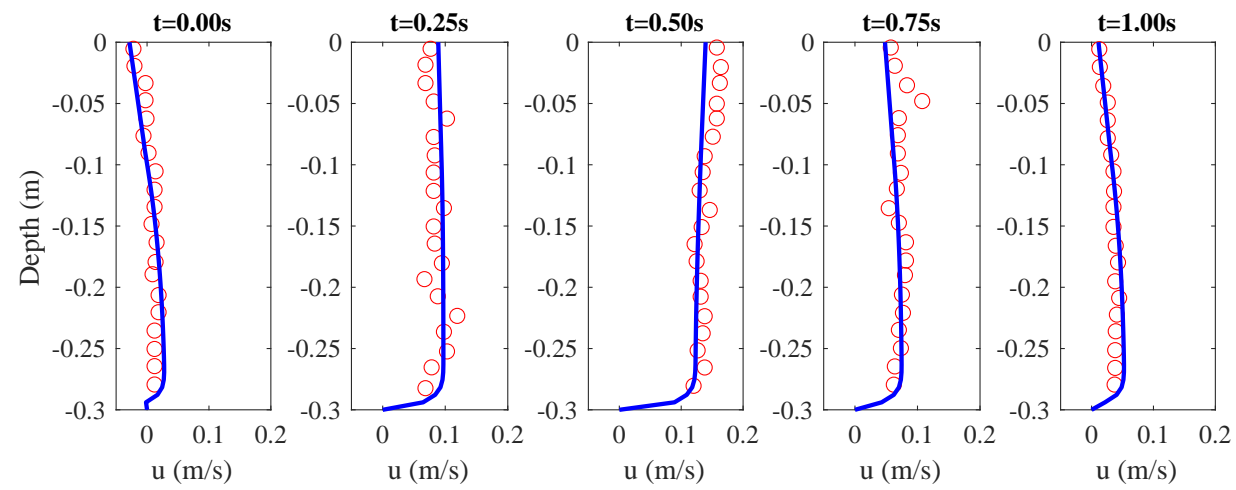

Fig. 22. Validation of horizontal-velocity profiles for wave-current cases (WC1, WC2 and WC3) against experimental data [Umeyama, 2011]. Note: $z=0$ denotes the mean water level in the experiments. 


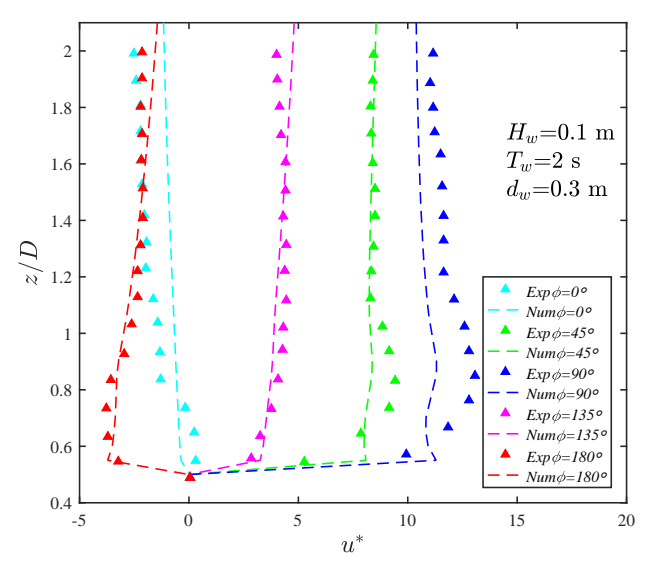

Fig. 23. Validation of the vertical distribution of the dimensionless horizontal fluid velocity through the centre of the pipeline $(z / D)$ for different wave phases against experimental data [Mattioli et al., $2012]$.

\section{A3 Comparison with the Hsu and Jeng [1994]'s analytical solution and Liu et al. [2015]'s experimental data of pore pressure $\tilde{p}_{s}$}

As introduced previously, the wave-seabed interaction mechanisms can be described by a set of analytical solutions. Among these, Hsu and Jeng [1994] developed an analytical solution for the wave-induced soil response for an unsaturated anisotropic seabed of finite thickness subject to a three-dimensional wave system. The case with a fully saturated isotropic seabed of finite thickness is also available for validation of the wave-induced oscillatory soil response without a marine structure [Jeng and Hsu, 1996; Jeng, 2013]. Figure 24 shows the comparison of the maximum pore pressure $\left(\left|\tilde{p}_{s}\right| / p_{0}\right)$ along the depth of the seabed between their analytical solutions and the numerical results produced by the present model. As shown, comparisons of the experimental data [Liu et al., 2015] with the numerical results as depicted in Figure 24 and Figure 25 clearly show that the computational results of the present model for simulating the soil of finite thickness agree well with both the analytical solution and the experimental data.

\section{A4 Comparison with the Turcotte et al. [1984]'s laboratory experiment and Cheng and Liu [1986]'s numerical solution of wave-induced soil response around a fully buried pipeline.}

In the next validation, the present model is compared with the laboratory experiments of Turcotte et al. [1984], in which the wave-induced soil response around a fully buried pipeline based on wave tank tests was explored. The tests were carried out in a $16 \mathrm{~m}$ long, $0.76 \mathrm{~m}$ wide wave tank. At the mid-length of the wave tank, 


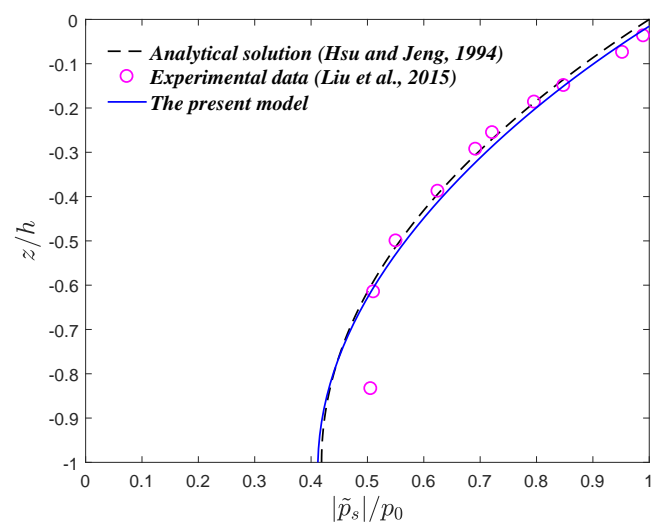

(a)

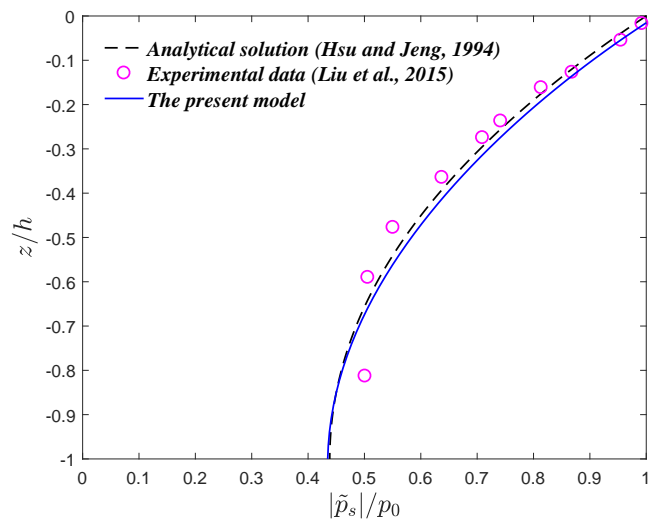

(b)

Fig. 24. Comparison of the numerical results of the vertical distribution of maximum pore pressure against the laboratory experimental data [Liu et al., 2015] and the analytical solution [Hsu and Jeng, 1994] for cases with (a) $S_{r}=0.996$ and (b) $S_{r}=0.951$.

a PVC pipe $\left(D_{p}=0.168 \mathrm{~m}\right)$ was fully buried $(e=0.107 \mathrm{~m})$ within an impermeable trench (4.57 $\mathrm{m}$ long and $0.826 \mathrm{~m}$ deep). Also, the centre of the pipe is less than 0.167 $m$ below the mud-line. Next, the comparison with numerical results [Cheng and Liu, 1986] by applying the Boundary Integral Equation Method(BIEM) is presented.

Figure 26 illustrates the distribution of the wave-induced maximum pore pressure $\left(\left|\tilde{p}_{s}\right| / p_{0}\right)$ along the outer surface of the pipeline $\left(\theta_{p}\right)$ for three wave conditions: (a) $T=0.9 \mathrm{~s}, L=1.25 \mathrm{~m}$, and $H=0.0524 \mathrm{~m}$; (b) $T=1.75 \mathrm{~s}, L=3.54 \mathrm{~m}$, and $H=0.143$ $\mathrm{m}$; and (c) $T=2.3 \mathrm{~s}, L=4.91 \mathrm{~m}$, and $H=0.0302 \mathrm{~m}$. Overall, the present model captures the essential features of the laboratory experiments [Turcotte et al., 1984] and numerical solutions [Cheng and Liu, 1986]. 


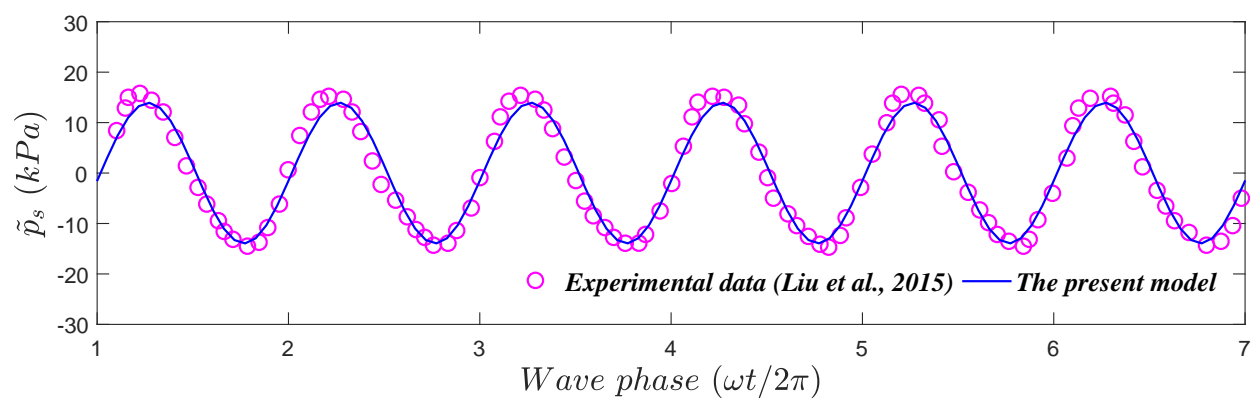

(a)

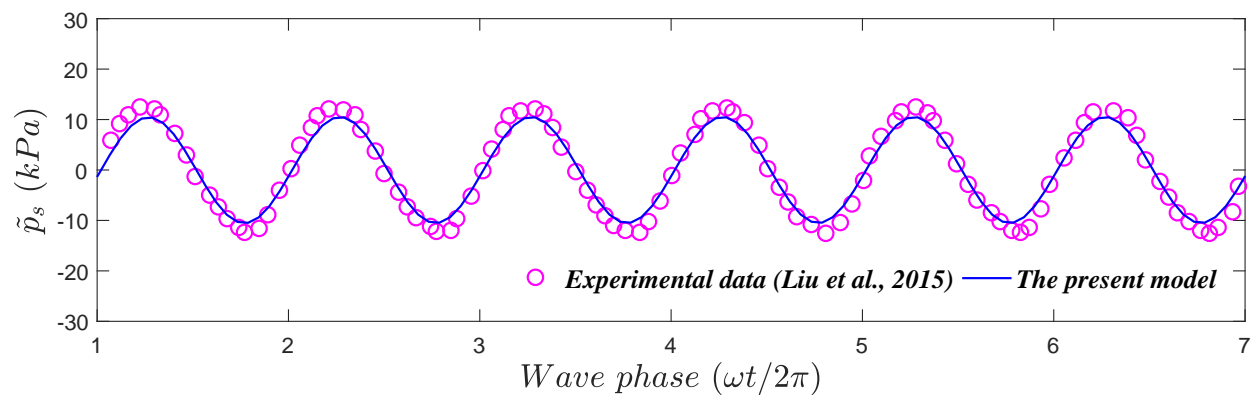

(b)

Fig. 25. Comparison of wave-induced pore pressure with the laboratory experimental data [Liu et al., 2015] for cases with $S_{r}=0.951$ at the depth (a) $z=-0.067 \mathrm{~m}$ and (b) $z=-0.267 \mathrm{~m}$

In summary, five sets of experiential data available in the literature (including the case of Sun et al. [2018] in section 2) are reproduced to verify the present FVM model. Overall, good agreements between the numerical and experimental results indicate that the present wave model can capture the behaviour of waves interacting with continuous currents. Also, the present seabed model in OpenFOAM can accurately simulate the wave-induced dynamic seabed response involving both a fully-buried and trenched pipeline.

\section{References}

Barth, T. J. [1992] Aspects of unstructured grids and finite- volume solvers for the euler and navier-stokes equations, Special Course on Unstructured Grid Methods for Advection Dominated Flows, AGARD Report N92-27677, pp. 18-34.

Biot, M. A. [1941] General theory of three-dimensional consolidation, Journal of Applied Physics 26(2), 155-164.

Cheng, A. H. D. and Liu, P. L.-F. [1986] Seepage force on a pipeline buried in a 


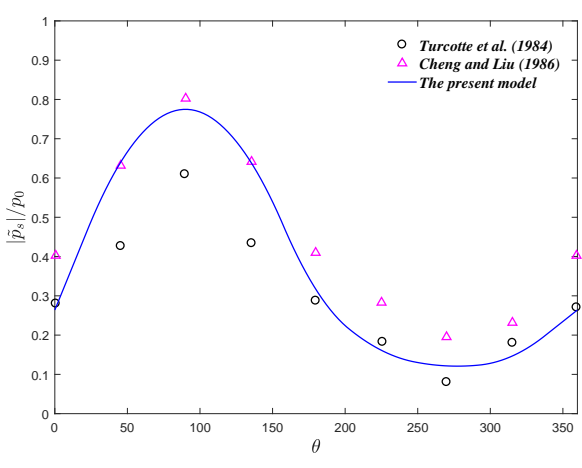

(a)

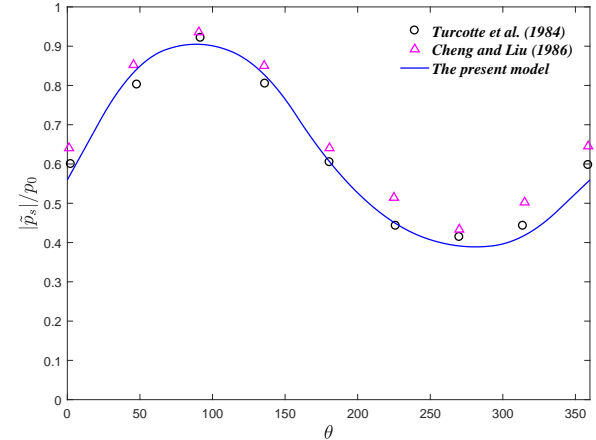

(b)

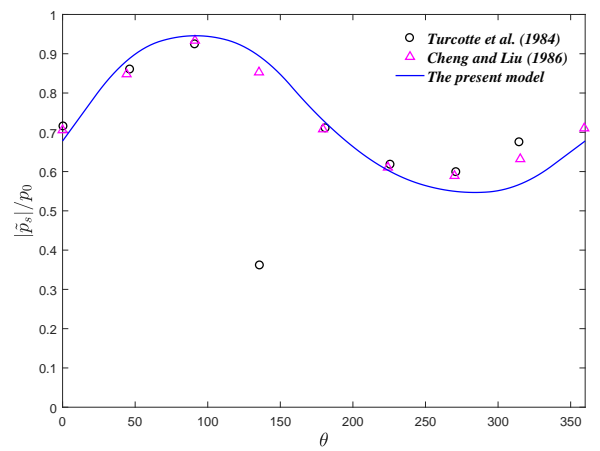

(c)

Fig. 26. Comparison of numerical results of wave-induced maximum pore pressure $\left(\left|\tilde{p}_{s}\right| / p_{0}\right)$ along the periphery of the pipeline $(\theta)$ with the experimental data [Turcotte et al., 1984] and the numerical solution [Cheng and Liu, 1986] for three different wave conditions:(a) $T=0.9 \mathrm{~s}, L=1.25 \mathrm{~m}$, and $H=0.0524 \mathrm{~m}$; (b) $T=1.75 \mathrm{~s}, L=3.54 \mathrm{~m}$, and $H=0.143 \mathrm{~m}$; and (c) $T=2.3 \mathrm{~s}, L=4.91 \mathrm{~m}$, and $H=0.0302$ $m$.

poroelastic seabed under wave loading, Applied Ocean Research 8(1), 22-32.

del Jesus, M., Lara, J. L. and Losada, I. J. [2012] Three-dimensional interaction of waves and porous coastal structures: Part I: Numerical model formulation, Coastal Engineering 64, 57-72.

Duan, L. L., Liao, C. C., Jeng, D.-S. and Chen, L. Y. [2017] 2d numerical study of wave and current-induced oscillatory non-cohesive soil liquefaction around a parrtially buried pipeline in a trench, Ocean Engineering 135, 39-51.

Fenton, J. D. [1985] Wave forces on vertical walls, Journal of Waterway, Port, Coastal and Ocean Engineering, ASCE 111(4), 693-718.

Fredsøe, J. [2016] Pipeline-seabed interaction, Journal of Waterway, Port, Coastal and Ocean Engineering, ASCE 142(6), 03116002.

Gao, F. P., Jeng, D.-S. and Sekiguchi, H. [2003] Numerical study on the interaction 
between non-linear wave, buried pipeline and non-homogeneous porous seabed, Computers and Geotechnics 30(6), 535-547.

Gao, F.-P. and Wu, Y.-X. [2006] Non-linear wave induced transient response of soil around a trenched pipeline, Ocean Engineering 33, 311-330.

Higuera, P., Lara, J. L. and Losada, I. J. [2013] Realistic wave generation and active wave absorption for navier-stokes models: Application to openfoam, Coastal Engineering 71, 102-118.

Hsu, J. R. C. and Jeng, D.-S. [1994] Wave-induced soil response in an unsaturated anisotropic seabed of finite thickness, International Journal for Numerical and Analytical Methods in Geomechanics 18(11), 785-807.

Hsu, J. R. C., Jeng, D.-S. and Lee, C. P. [1995] Oscillatory soil response and liquefaction in an unsaturated layered seabed, International Journal for Numerical and Analytical Methods in Geomechanics 19(12), 825-849.

Jeng, D.-S. [1997] Wave-induced seabed instability in front of a breakwater, Ocean Engineering 24(10), 887-917.

Jeng, D.-S. [2003] Wave-induced sea floor dynamics, Applied Mechanics Reviews 56(4), 407-429.

Jeng, D.-S. [2013] Porous Models for Wave-seabed Interactions (Springer).

Jeng, D.-S. and Cheng, L. [2000] Wave-induced seabed instability around a buried pipe in a poroelastic seabed, Ocean Engineering 27, 127-1464.

Jeng, D.-S. and Hsu, J. R. C. [1996] Wave-induced soil response in a nearly saturated seabed of finite thickness, Géotechnique 46(3), 427-440.

Jeng, D.-S. and Lin, Y. S. [1999] Wave-induced pore pressure around a buried pipeline in gibson soil: Finite element analysis, International Journal for $\mathrm{Nu}$ merical and Analytical Methods in Geomechanics 23(13), 1559-1578.

Liang, Z. D. and Jeng, D.-S. [2018] 3-D numerical model for wave-induced seabed response around an offshore pipeline, The 20th International Conference on Ocean Engineering (ICOE2018) (Melbourne, Australia), p. (CD ROM).

Lin, Z., Guo, Y. K., Jeng, D.-S., Liao, C. C. and Rey, N. [2016] An integrated numerical model for wave-soil-pipeline interaction, Coastal Engineering 108, 2535.

Lin, Z., Pokrajac, D., Guo, Y., Jeng, D.-S., Tang, T., Rey, N., Zheng, J. and Zhang, J. [2017] Investigations of nonlinear wave-induced seabed response around monopile foundation, Coastal Engineering 121, 197-211.

Liu, B., Jeng, D.-S., Ye, G. L. and Yang, B. [2015] Laboratory study for pore pressures in sandy deposit under wave loading, Ocean Engineering 106, 207-219.

Liu, P. L.-F., Lin, P., Chang, K. A. and Sakakiyama, T. [1999] Numerical modelling of wave interaction with porous structures, Journal of Waterway, Port, Coastal and Ocean Engineering, ASCE 125(6), 322-330.

Liu, X. and García, M. H. [2007] Numerical investigation of seabed response under waves with free-surface water flow, International Journal of Offshore and Polar Engineering 17(02), 97-104. 
Madsen, O. S. [1978] Wave-induced pore pressures and effective stresses in a porous bed, Géotechnique 28(4), 377-393.

Mao, Y. [1986] The interaction between a pipeline and an erodible bed, $\mathrm{PhD}$ thesis, Institute of Hydrodynamics and Hydraulic Engineering.

Mattioli, M., Alsina, J. M., Mancinelli, A., Miozzi, M. and Brocchini, M. [2012] Experimental investigation of the nearbed dynamics around a submarine pipeline laying on different types of seabed: the interaction between turbulent structures and particles, Advances in Water Resources 48, 31-46.

Nago, H., Maeno, S., Matsumoto, T. and Hachiman, Y. [1993] Liquefaction and densification of loosely deposited sand bed under water pressure variation, Proceeding of the 3rd international offshore and Polar Engineering Conference, Singapore, pp. $578-584$.

Seed, H. B. and Rahman, M. S. [1978] Wave-induced pore pressure in relation to ocean floor stability of cohesionless soils, Marine Geotechnology 3(2), 123-150.

Sumer, B. M., Fredsøe, J., Christensen, S. and Lind, M. L. [1999] Sinking/floatation of pipelines and other objects in liquefied soil under waves, Coastal Engineering 38, 53-90.

Sumer, B. M., Truelsen, C., Sichmann, T. and Fredsøe, J. [2001] Onset of scour below pipelines and self-burial, Coastal engineering 42(4), 313-335.

Sun, K., Zhang, J.-S., Gao, Y., Guo, Y., Liang, Z. and Jeng, D.-S. [2018] Ocean waves propagating over a partially buried pipeline in a trench layer: Experimental study, Ocean Engineering (Submitted).

Tang, T., Hededal, O. and Cardill, P. [2015] On finite volume method implementation of poroelasto- plasticity soil model, International Journal for Numerical and Analytical Methods in Geomechanics 39(13), 1410-1430.

Teh, T. C., Palmer, A. C. and Damgaard, J. S. [2003] Experimental study of marine pipelines on unstable and liquefied seabed, Coastal Engineering 50, 1-17.

Turcotte, B. R., Liu, P. L.-F. and Kulhawy, F. H. [1984] Laboratory evaluation of wave tank parameters for wave-sediment interaction, Tech. rep., Joseph F. Defree Hydraulic Laboratory, School of Civil and Environmental Engineering, Cornell University.

Ulker, M. and Rahman, M. S. [2009] Response of saturated and nearly saturated porous media: Different formulations and their applicability, International Journal for Numerical and Analytical Methods in Geomechanics 33(5), 633-664.

Umeyama, M. [2011] Coupled piv and ptv measurements of particle velocities and trajectories for surface waves following a steady current, Journal of Waterway, Port, Coastal and Ocean Engineering, ASCE 137(2), 85-94.

Wen, F., Jeng, D.-S. and Wang, J. H. [2012] Numerical modeling of response of a saturated porous seabed around an offshore pipeline considering non-linear wave and current interactions, Applied Ocean Research 35, 25-37.

Yamamoto, T., Koning, H., Sellmeijer, H. and Hijum, E. V. [1978] On the response of a poro-elastic bed to water waves, Journal of Fluid Mechanics 87(1), 193-206. 
Ye, J. and Jeng, D.-S. [2012] Response of seabed to natural loading-waves and currents, Journal of Engineering Mechanics, ASCE 138(6), 601-613.

Zen, K. and Yamazaki, H. [1990] Mechanism of wave-induced liquefaction and densification in seabed, Soils and Foundations 30(4), 90-104.

Zen, K. and Yamazaki, H. [1991] Field observation and analysis of wave-induced liquefaction in seabed, Soils and Foundations 31(4), 161-179.

Zhao, H., Jeng, D.-S., Guo, Z. and Zhang, J.-S. [2014] Two-dimensional model for pore pressure accumulations in the vicinity of a buried pipeline, Journal of Offshore Mechanics and Arctic Engineering, ASME 136, 042001.

Zhou, C., Li, G., Dong, P., Shi, J. and Xu, J. [2011] An experimental study of seabed responses around a marine pipeline under wave and current conditions, Ocean Engineering 38(1), 226-234.

Zhou, X. L., Jeng, D.-S., Ye, Y.-G. and Wang, J. H. [2013] Wave-induced seabed response around buried pipeline under wave loading and liquefaction, Ocean Engineering 72, 195-208.

Zhou, X. L., Wang, J. H., Zhang, J. and Jeng, D.-S. [2014] Wave and current induced soil response around a submarine pipeline in an anisotropic seabed and liquefaction, Ocean Engineering 75(112-127). 